\title{
Labor Mobility: Implications for Asset Pricing
}

\author{
ANDRÉS DONANGELO*
}

\begin{abstract}
Labor mobility is the flexibility of workers to walk away from employers in response to better opportunities. I develop a model in which labor flows make bad times worse for shareholders who are left with capital that is less productive. The model shows that firms face greater operating leverage by providing flexibility to mobile workers. I construct an empirical measure of labor mobility consistent with the model and document an economically significant cross-sectional relation between labor mobility, operating leverage, and expected returns. I find that firms in highly mobile industries earn returns 5.3\% higher than those in less mobile industries.
\end{abstract}

\footnotetext{
*Andrés Donangelo is with the Finance Department, University of Texas at Austin. This paper is based on the first chapter of my PhD dissertation at the University of California at Berkeley entitled "Labor Mobility and the CrossSection of Expected Returns". I am very grateful to the members of my dissertation committee, Nicolae Gârleanu (Chair), Martin Lettau, Dmitry Livdan, and Ulrike Malmendier for their guidance and many helpful discussions. I thank Aydogan Alti, Jonathan Berk, Maria Cecilia Bustamante, Esther Eiling, Andrew Karolyi, Hayne Leland, Miguel Palacios, Christine Parlour, Mitchell Petersen, Selale Tuzel, Johan Walden, Lu Zhang, and seminar participants at Arizona State University, Boston College, Columbia University, Copenhagen Business School, Cornell University, Federal Reserve Board, Indiana University, London Business School, Massachusetts Institute of Technology, Northwestern University, Ohio State University, Stanford University, University of California at Berkeley, University of Illinois at Urbana-Champaign, University of Southern California, University of Texas at Austin, WFA's 2011 Meeting, and the $19^{\text {th }}$ Mitsui Finance Symposium for helpful comments and discussions. Errors are solely my responsibility. I gratefully acknowledge the Dean Witter, White, and NASDAQ OMX Educational foundations for financial support. This version: August 2012.
} 
Firms do not own their most important production factor-labor-but merely rent it from willing individuals who have the flexibility to leave. This paper studies how the lack of full control over labor represents a source of risk for the owners of firms. In particular, the paper addresses the following question: are firms employing workers who have labor skills portable across industries more exposed to systematic risk than firms in which workers have less portable skills? The answer to this question is important for a number of reasons. First, it offers information on the source of a firm's systematic risk by linking workers' decisions to asset price dynamics. Second, it sheds light on why observable properties of the workforce employed in an industry should explain cross-sectional differences in expected asset returns. Finally, it motivates empirical evidence that suggests that labor mobility represents an economically significant mechanism for asset pricing: zero-net investment portfolios that hold long positions in stocks of high-mobility industries and short positions in stocks of low-mobility industries earn an annual return spread of over 5\%, after controlling for median firm characteristics known to predict expected stock returns.

I establish the link between workers' employment decisions and their employers' risk exposure in a dynamic model of an industry in which firms compete for workers in a partially segmented labor market. The less segmented the labor market is, the greater the flexibility workers have to move in and out of the industry. This flexibility, which I denote labor mobility, is determined by the nature of labor skills required by the productive technology common to all firms in the industry. In particular, the more industry-specific the required labor skills are, the less mobile the labor supply is. As an example: the labor supply in the health care industry is relatively less mobile than that of the wholesale trade industry, since several of the workers in the former have occupations that require a significant level of industry-specific skills (e.g., medical doctors, nurses, and health technicians), while workers in the latter have less industry-specific occupations (e.g., salespersons, logistics analysts, and financial analysts).

The model predicts that labor mobility translates into a labor-induced form of operating leverage that amplifies firms' existing exposure to systematic risk. ${ }^{1}$ Intuitively, the risk of firms in-

\footnotetext{
${ }^{1}$ This form of operating leverage is similar to the concept of "labor leverage" discussed by Gourio (2007).
} 
creases with the degree of their inflexibility in adjusting unit labor costs of mobile workers to mitigate the impact of industry shocks. Mobile industries, such as the wholesale trade industry mentioned before, rely on workers with more general labor skills that allow them to search for higher wages across many industries. Less elastic wages make the level of labor employed and, consequently, cash flows to shareholders more sensitive to industry-specific shocks, which affects systematic risk in a way similar to that of "traditional" operating leverage, defined as the ratio of fixed over variable operating costs. For instance, Davis and Haltiwanger (2001) document significant flows of workers to and from the highly mobile manufacturing sector between 1972 and 1988 in response to oil price shocks. The exposure to flows of labor in sync with oil shocks amplify risk for investors, which should demand higher expected returns to hold manufacturing stocks.

Industry-specific labor mobility is not directly observable and represents a challenge for the study of factor mobility. ${ }^{2}$ To overcome this problem, I propose an indirect measure of labor mobility based on the average occupation dispersion of employed workers in an industry. I construct the measure of labor mobility with data from the Bureau of Labor Statistics' (BLS) on the distribution of workers across occupations and industries from 1988 to 2011. Workers in occupations concentrated in a few industries are associated with industry specialists with low labor mobility, while workers in occupations dispersed across the economy are associated with generalists with high mobility. For example, the fact that most workers in the "airline pilots" occupation are concentrated in the "scheduled air transportation" industry suggests that airline pilots have low inter-industry mobility. On the other extreme, the fact that workers in the "network and computer systems administrators" are found across several industries supports the hypothesis that these workers are mobile. Occupation dispersion is used as a proxy for (the inverse of) human capital specificity. The measure is consistent with growing evidence in the Labor Economics literature that labor mo-

\footnotetext{
${ }^{2}$ A related challenge, specific to Finance, is that existing proxies for labor mobility used in the field of Labor Economics are not directly applicable to Asset Pricing given their common treatment of firm shocks as exogenous events. The strand of the Labor Economics most closely related to this paper is on human capital specificity. Examples of this work are Neal (1995), Parent (2000), and Kambourov and Manovskii (2009a). This strand of the literature estimates human capital specificity from labor income losses after observed job separations, which are often triggered by underlying firm shocks and subject to endogeneity problems in Asset Pricing research.
} 
bility is driven by the level of occupation-specificity of human capital. ${ }^{3}$ The relation between a worker's human capital specificity and occupation is illustrated by the following quote from Kambourov and Manovskii (2009b, pg. 64):

“(...) it appears natural to expect that when a truck driver switches industries (say, from wholesale trade to retail trade) or employers, he loses less of his human capital generated by the truck-driving experience than when he switches his occupation and becomes a cook."

I find evidence that the labor mobility measure (LM) is positively related to the sensitivity, or elasticity, of operating cash flows to industry shocks. This elasticity is observationally similar to the effect of operating leverage on operating cash flows. I construct a proxy for operating leverage defined as the industry-level elasticity of capital payments to total factor productivity (TFP) growth using KLEMS data obtained from BLS. This finding supports the model's prediction that labor mobility is associated a labor-induced form of operating leverage which lead to higher sensitivity to industry shocks.

The evidence suggests that investors demand higher expected stock returns for holding highLM stocks relative to low-LM stocks. A zero-investment portfolio, long high-LM, and short lowLM stocks (portfolio H-L), earns significantly positive excess returns, even after adjusting the portfolio's underlying stock returns for firm characteristics, such as size and book-to-market, as well as past returns. I find similar results when I use measures of implied cost of capital as proxies for expected returns. Moreover, the economic magnitude of the effect is large. Using panel data regressions of ex-post realized firm-level returns on a lagged measure of labor mobility, in addition to firm-level controls, I confirm the relationship between LM and cross-sectional predictability of stock returns. I find that a one standard deviation increase in LM in the cross-section is associated with an increase of around $2 \%$ in annual stock returns for individual firms.

The model assumes an exogenously given pricing kernel and is therefore silent on the ultimate

\footnotetext{
${ }^{3}$ See for example Shaw $(1984,1987)$ and Kambourov and Manovskii (2009a, 2009b).
} 
source of aggregate risk in the economy. Although outside the scope of the model, a natural empirical question is to investigate the relation between the LM premium, risk factors, and variables connected to the business cycle. I find a positive relation between conditional market betas and LM. I estimate conditional betas as in Lewellen and Nagel (2006), which do not require the specification of conditioning information. The conditional CAPM is able to price portfolios of stocks sorted on LM, while the unconditional CAPM and other traditional multifactor models fail. More generally, I show that the LM premium fluctuates in sync with standard risk factors commonly used in the literature. This finding is consistent with LM being a risk amplification mechanism for stockholders.

Related to this paper is a broad asset-pricing literature that explores the relation between firms' characteristics and predictability in the cross-section of asset returns. ${ }^{4}$ To this literature, this paper adds labor mobility as a theoretically motivated and observable industry property that affects firm risk and expected stock returns.

The novel labor mobility channel also contributes to the literature that discusses alternative mechanisms that generate labor-induced operating leverage. Danthine and Donaldson (2002) discuss a mechanism in which a counter-cyclical capital-to-labor share leads to labor-induced operating leverage in a general equilibrium setting. In their model, wages are less volatile than profits, due to labor contracts that provide labor-risk insurance to workers. Kuehn, Petrosky-Nadeau, and Zhang (2012) incorporate search frictions and sticky wages into a DSGE model that generates realistic labor and financial markets moments. Gourio (2007) proposes a model in which labor intensity and cross-sectional productivity heterogeneity amplify cash-flow volatility.

A small but growing strand of the literature relate labor market frictions to the value of the firm. Bazdresch, Belo, and Lin (2009) and Merz and Yashiv (2007) incorporate labor, modeled as a production-factor analogous to physical capital, into standard q-theory asset-pricing models, ${ }^{5}$ to

\footnotetext{
${ }^{4}$ A small sample of this literature includes Basu (1983), Bhandari (1988), Fama and French (1992), Chan and Chen (1991), Dechow, Hutton, Meulbroek, and Sloan (2000), Griffin and Lemmon (2002), Hou and Robinson (2006), and Gourio (2007).

${ }^{5}$ See for example Cochrane (1991) and Zhang (2005).
} 
link a firm's hiring decisions with firm value and stock returns, respectively. Chen, Kacperczyk, and Ortiz-Molina (2011) find that the cost of capital is higher for industries with high unionization levels, which in turn lowers the flexibility on the demand side of labor. My work departs from this literature mainly by focusing on the flexibility of the supply side of labor, i.e., the worker, as opposed to labor-adjustment frictions for the firm.

This paper builds upon the idea that mobile workers effectively carry some of the firm's capital productivity when they leave an industry. A recent strand in the finance literature discusses a similar mechanism: the threat of skilled employees that can carry organization capital (OC) away from an employer. Lustig, Syverson, and Nieuwerburgh (2011) discuss the impact of intraindustry inter-firm portability of OC for executives' compensation and firm value. They show that high levels of portability reduce the effectiveness of labor contracts that insure executives against industry-specific labor risk. Eisfeldt and Papanikolaou (2012) show that firms with high levels of OC are more exposed to priced technology frontier shocks that attract key talent away from the firm.

Related to the theoretical approach of this paper are studies of the cross-section of returns based on micro-level decisions through dynamic optimization. The main departure point from the literature is that, in my work, labor decisions made by workers affect firm risk, whereas the determinant of firm risk are decisions made by equity holders on investments in Berk, Green, and Naik (1999), Carlson, Fisher, and Giammarino (2004), and Zhang (2005), or on hiring, as in Bazdresch et al. (2009).

The rest of the paper proceeds as follows. Section I presents the model. Section II presents the empirical tests, and Section III concludes. 


\section{The Model}

\section{A. Setup}

The model represents an industry composed of a large number of firms and workers. To keep the model tractable, and to focus on the effect of micro-level decisions on firm risk, I follow Berk et al. (1999) and take the pricing kernel as exogenous. The dynamics of the pricing kernel $\Lambda$ are given by:

$$
d \Lambda_{t}=-r \Lambda_{t} d t-\eta \Lambda_{t} d Z_{t}^{\lambda}
$$

where $d Z^{\lambda}$ is a Wiener processes that represents the single underlying source of systematic risk in the model, $r>0$ is the instantaneous risk-free rate, and $\eta>0$ is the market price of risk in the economy.

Firms have access to a perfectly competitive labor market composed by a continuum of workers with heterogeneous mixes of two types of labor skills: industry-specific, which can only be employed inside the industry, and general, which, for simplicity, can only be employed outside the industry. Firms are identical within an industry and are represented by an aggregate industry-firm with a Cobb-Douglas technology over industry-specific labor skills and capital. To keep the focus on the dynamics of labor, capital is assumed to be fixed and normalized to unity. ${ }^{6}$ Output is given by:

$$
Y_{t}=A_{t} L_{t}^{\alpha}
$$

where $L$ denotes the mass of industry-specific labor skills employed, $0<\alpha<1$ is the output

\footnotetext{
${ }^{6}$ A simple extension of the model with investments is presented in the Supplementary Appendix.
} 
elasticity of labor, and $A$ denotes total factor productivity (TFP) that follows the diffusion process:

$$
d A_{t}=A_{t} \sigma_{\mathrm{A}}^{\lambda} d Z_{t}^{\lambda}+A_{t} \sigma_{\mathrm{A}}^{\varepsilon} d Z_{t}^{\varepsilon}
$$

where $d Z^{\varepsilon}$ is a Wiener processes unrelated to $d Z^{\lambda}$ that represents industry-specific idiosyncratic risk.

Workers have permanent occupations based on their endowed composition of labor skills. For convenience, occupations are labeled by the index $j>0$ in decreasing order of their associated ratio of industry-specific to general labor skills, which is given by:

$$
l_{j} \equiv\left(\frac{\delta}{j}\right)^{1-\delta}, \text { where } 0<\delta<1
$$

The parameter $\delta$ determines the level of generality of labor skills required by the productive technology and therefore represents the level of labor mobility in the industry. Intuitively, $\delta$ captures the degree of integration of the labor supply in the industry to that of the rest of the economy, as illustrated in Figure 1. In particular, $\delta$ is related to the degree of similarity between industry specialists (i.e., workers in "low-j" occupations) and generalists (i.e., workers in "high-j" occupations). ${ }^{7}$ In the immobile case, i.e., $\delta \rightarrow 0$, industry specialists cannot leave and generalists cannot enter the industry, so that the industry's labor supply is fully segmented from the rest of the economy. In the fully mobile case, i.e., $\delta \rightarrow 1$, there is no distinction between an industry specialist and a generalist, so that labor markets are perfectly integrated.

$$
<<\text { Figure } 1 \text { here }>>
$$

Hourly wages per unit of general skills are exogenously given by the diffusion:

$$
d W_{t}^{\mathrm{G}}=W_{t}^{\mathrm{G}} \sigma_{\mathrm{G}}^{\lambda} d Z_{t}^{\lambda}+W_{t}^{\mathrm{G}} \sigma_{\mathrm{G}}^{v} d Z_{t}^{v}
$$

\footnotetext{
${ }^{7}$ Note that an occupation $j$ is solely determined in the model by the composition $\left(l_{j}\right)$, and not by the level of labor skills. In this sense, industry specialization and labor mobility are unrelated to the level of human capital in the model.
} 
where "G" stands for "general skills" and $d Z^{v}$ is a Wiener process independent from $d Z^{\lambda}$ and $d Z^{\varepsilon}$ that represents the non-systematic portion of shocks to growth in wages for general skills.

\section{B. Competitive Equilibrium}

Perfect competition in the goods and labor markets drive firms to equate the marginal profitability of industry-specific skills employed to hourly wages in the industry. Total operating profits are defined as the residual cash flows of the firm after wages are paid. Hourly wages and total operating profits are:

$$
\begin{aligned}
& W_{t}^{\mathrm{S}}=\alpha A_{t} L_{t}^{\alpha-1} \quad \text { and } \\
& \Pi_{t}=Y_{t}-L_{t} W_{t}^{\mathrm{S}}=(1-\alpha) A_{t} L_{t}^{\alpha}, \text { respectively }
\end{aligned}
$$

where the superscript "S" stands for "specific skills", which are the only type of labor skills productive and therefore compensated inside the industry.

Workers continuously make decisions to work either inside or outside the industry based on their occupation and on prevailing wages for specific and general labor skills, $W^{\mathrm{S}}$ and $W^{\mathrm{G}}$. A worker in occupation $j$ is indifferent between staying and leaving when her expected labor income is the same inside and outside the industry, as given by the indifference condition:

$$
W_{t}^{\mathrm{S}} l_{j}=W_{t}^{\mathrm{G}}
$$

The identify of the marginal occupation $j_{t}^{*}$ that satisfies the indifference condition (8) at time $t$ is:

$$
j_{t}^{*}=\delta x_{t}^{\frac{1}{1-\alpha \delta}}, \quad \text { where } \quad x_{t} \equiv \frac{\alpha A_{t}}{W_{t}^{\mathrm{G}}}
$$

Note that the random variable $x$ equals the ratio of hourly wages inside and outside the industry in the special case when labor supply is equal to one. Intuitively, $x$ represents the relative productivity 
of the industry with respect to that of the rest of the economy.

Labor markets are in equilibrium when: (1) all workers in occupations $j<j_{t}^{*}$ strictly prefer to remain inside; and (2) all workers in occupations $j>j_{t}^{*}$ strictly prefer to remain outside the industry. The equilibrium level of employed labor skills useful inside the industry is given by:

$$
L_{t}^{*} \equiv \int_{0}^{j_{t}^{*}} l_{j} d j=x_{t}^{\frac{\alpha \delta}{1-\alpha \delta}}
$$

Equilibrium operating profits $\left(\Pi_{t}^{*}\right)$ are found by plugging the equilibrium employment above into Equation (7):

$$
\Pi_{t}^{*}=(1-\alpha) A_{t} x_{t}^{\frac{\alpha \delta}{1-\alpha \delta}}
$$

\section{Labor Induced Operating Leverage}

Having derived the dynamics of cash flows, I present below the mechanism in which labor mobility is translated into a labor-induced form of operating leverage for the firm. The basic idea of the mechanism is that inflows of mobile workers increase cash flows when the performance of the industry is relatively high while outflows of mobile workers reduce cash flows when performance is relatively low. A simple inspection of Equation (11) confirms this intuition by revealing that the effect of labor mobility $\delta$ on operating profits is in fact positively related to the relative productivity of the industry, $x$, which is defined in Equation (9). In the fully immobile case, i.e., $\delta \rightarrow 0$, the only source of uncertainty for operating profits is the absolute productivity level $A$. When an industry employs mobile workers, i.e., $\delta>0$, operating profits also have a positive loading of magnitude $\frac{\alpha \delta}{1-\alpha \delta}$ on shocks to the industry's relative productivity $x$.

In order to quantify the effect of labor mobility on firm risk amplification, I first define a measure of the sensitivity of cash flow growth to the fundamental source of risk for the industry, i.e. shocks to TFP growth, $\Theta$, which I denote simply as “operating leverage”. Operating leverage, 
$\Theta$, is defined as the scaled covariance of equilibrium operating profit growth and TFP growth: ${ }^{8}$

$$
\Theta \equiv \operatorname{Cov}\left[\frac{d \Pi}{\Pi}, \frac{d A}{A}\right] / \operatorname{Var}\left[\frac{d A}{A}\right]-1
$$

We can immediately deduce from the definition above that the level of operating leverage of firms in an immobile industry is zero, i.e., $\Theta^{*}(0)=0$, since its operating profits are linearly related to TFP (A), as shown in Equation (11), and since firms do not incur any fixed costs to operate. In equilibrium, operating leverage is given by:

$$
\Theta^{*}(\delta)=\frac{\delta \alpha}{1-\delta \alpha}\left(1-\frac{\sigma_{\mathrm{A}}^{\lambda} \sigma_{\mathrm{G}}^{\lambda}}{\sigma_{\mathrm{A}}^{2}}\right),
$$

where $\sigma_{\mathrm{A}}^{2} \equiv\left(\sigma_{\mathrm{A}}^{\lambda}\right)^{2}+\left(\sigma_{\mathrm{A}}^{\varepsilon}\right)^{2}$ is the variance of TFP $(A)$ growth. The first term on the right hand side of Equation (13), $\frac{\alpha \delta}{1-\alpha \delta}$, is increasing in labor mobility $\delta$, and captures the loading of operating profits on the industry's relative productivity, $x$, introduced in Equation (11). The second term, $1-\frac{\sigma_{\mathrm{A}}^{\lambda} \sigma_{\mathrm{G}}^{\lambda}}{\sigma_{\mathrm{A}}^{2}}$, is decreasing in the covariance between TFP growth, $\frac{d A}{A}$, and growth in wages for generalists, $\frac{d W^{\mathrm{G}}}{W^{\mathrm{G}}}$. When wages for generalists are sufficiently smooth or sufficiently uncorrelated to TFP shocks, the overall effect of labor mobility on operating leverage is positive. The following proposition formalizes this result:

Proposition 1 (Labor mobility and operating leverage). For all levels of labor mobility $(\delta)$ :

$$
\sigma_{\mathrm{A}}^{2}>\sigma_{\mathrm{A}}^{\lambda} \sigma_{\mathrm{G}}^{\lambda} \Leftrightarrow \frac{\partial \Theta(\delta)}{\partial \delta}>0
$$

The proposition follows directly from the definition of operating leverage, $\Theta$, presented in Equation (13).

\section{Valuation and Expected Returns}

Under mild assumptions, the positive effect of labor mobility on operating leverage also leads to an increase in firms' exposure to systematic risk and expected asset returns. To show this result, I

\footnotetext{
${ }^{8}$ Alternatively $\Theta$ is defined as the slope of a regression of operating profit growth on TFP growth minus one.
} 
start by deriving the value of the firm. In equilibrium, unlevered asset value $(V)$ equals the value of the discounted stream of operating profits:

$$
V_{t}=\mathrm{E}_{t}\left[\int_{t}^{\infty} \frac{\Lambda_{s}}{\Lambda_{t}} \Pi_{s}^{*} d s\right]
$$

Conditional on existing, the solution to Equation (14) is given by:

$$
V_{t}=\frac{\Pi_{t}^{*}}{r+\beta \eta-\mu_{\Pi}}
$$

where $\mu_{\Pi}$ is the instantaneous drift of operating profits' growth and

$$
\beta=\sigma_{\mathrm{A}}^{\lambda}+\frac{\alpha \delta}{1-\alpha \delta} \sigma_{\mathrm{A}}^{\lambda}-\frac{\alpha \delta}{1-\alpha \delta} \sigma_{\mathrm{G}}^{\lambda}
$$

is the loading on systematic risk. ${ }^{9}$ See Appendix A for a derivation of Equation (15). Equation (15) is well defined when $\mu_{\Pi}<r+\beta \eta$. The first term of the right side of Equation (16), $\sigma_{\mathrm{A}}^{\lambda}$, is unaffected by labor mobility and represents the baseline systematic risk that arises from the industry's productivity $A$. The second term and third terms have magnitudes that are increasing in labor mobility, $\delta$, and shed light on the two antagonistic effects of labor mobility on firm risk. The term $\frac{\alpha \delta}{1-\alpha \delta} \sigma_{\mathrm{A}}^{\lambda}$ is related to the additional loading on systematic risk given by the extra volatility in the quantity of labor employed. The term $-\frac{\alpha \delta}{1-\alpha \delta} \sigma_{\mathrm{G}}^{\lambda}$, represents the reduction in firm risk due to the exposure of the cost of labor to wages for general skills, $W_{\mathrm{G}}^{\lambda}$, which contain systematic risk. Since wages represent a cost for the firm, the latter effect is analogous to a short position in a risky asset, which effectively reduces the beta and lowers expected asset returns. The net effect of labor mobility depends on the systematic risk loadings of the TFP and wage growth, as formalized below:

Proposition 2 (Labor mobility and asset returns). For all levels of labor mobility $(\delta)$ :

\footnotetext{
${ }^{9}$ Note that, unlike traditional beta representations, $\beta$ is not scaled for aggregate risk. In order to do so, we would need to make additional assumptions about the economy.
} 


$$
\sigma_{\mathrm{G}}^{\lambda}<\sigma_{\mathrm{A}}^{\lambda} \Leftrightarrow \frac{\partial \beta}{\partial \delta}>0
$$

The Proposition follows directly from Equation (16).

\section{E. Labor Mobility and Inter-industry Concentration of Occupations}

A direct test of the implications of the model requires a ranking of industries based on the intrinsic mobility of workers to enter and exit an industry. Unfortunately, the level of labor mobility associated with an industry's technology, i.e., $\delta$, is unobservable. This section shows that, under plausible assumptions, we can use a measure of labor mobility based on the observable dispersion of occupations across industries to estimate the ranking of industries based on $\delta$. This result motivates the use of the proposed empirical measure introduced in the next section.

Let $0<\gamma_{j t} \leq 1$ denote inter-industry concentration of occupation $j$ at time $t$, assumed to be continuously differentiable and decreasing in the level of industry-specific specialization of the

occupation, i.e., $\frac{d \gamma_{j t}}{d j}<0$. The industry-level measure of concentration, denoted $\Gamma_{i t}$, is defined as the mean inter-industry occupation concentration across all occupations represented in the industry at time $t$ :

$$
\Gamma_{i t} \equiv \frac{\int_{0}^{j_{t}^{*}} \gamma_{j t} d j}{j_{t}^{*}}
$$

where $j^{*}$ is defined in Equation (9). The lemma below formalizes sufficient conditions for a positive relationship between expected occupation dispersion, $\mathrm{E}\left[\Gamma_{i}^{-1}\right]$, and labor mobility, $\delta$ :

Lemma 1 (Expected occupational dispersion and labor mobility). Let $z \equiv \log (x)$ be the unobservable logarithm of the relative performance of the industry, assumed to be stationary with $z \sim N[0, \sigma]$. If the volatility $z$, i.e., $\sigma$, is sufficiently low, then a ranking of industries sorted on $\mathrm{E}\left[\Gamma_{i}^{-1}\right]$ coincides with a ranking of industries sorted on $\delta$.

Proof: see Appendix B. 


\section{Empirical Evidence}

The model predicts a positive relationship between labor mobility and operating leverage, i.e., the sensitivity of operating cash flows to productivity shocks, (Proposition 1) and labor mobility and expected asset returns (Proposition 2). I first detail the methodology used for measuring labor mobility. I then proceed to present empirical support for the implications of labor mobility for operating leverage and expected asset returns.

\section{A. Measuring Labor Mobility}

The flexibility workers have to enter and exit an industry is intrinsically unobservable since it is determined by the nature of the labor skills offered by individuals and demanded by industries. To overcome this problem, I construct a proxy for labor mobility, denoted LM, based on the dispersion of occupations across industries. The basic intuition of the empirical measure LM is the following: workers in mobile occupations, by definition, can be employed across a larger number of industries than workers in immobile occupations. We should therefore expect to observe workers in mobile occupations more dispersed across industries than those in immobile occupations. Conversely, with no additional priors, we should expect that a dispersed occupation is likely to be more mobile than a concentrated one. This intuition is formalized by Lemma 1, which is presented in the previous section.

The empirical measure LM is justified by evidence in the labor economics literature indicating that the degree of specificity of labor skills is largely captured by workers' occupations and is a key determinant of their flexibility to switch jobs. Some examples of theoretical work in this literature are Becker (1964), Johnson (1979), and Grossman and Shapiro (1982), and some examples of empirical work are Willis (1985), Neal (1995), and Parent (2000). Kambourov and Manovskii (2009b) and Sullivan (2010) provide evidence that specific skills are more tied to an occupation than to a particular firm or industry. Tristao (2007) and Bardhan and Tang (2010) show that workers in occupations concentrated in a few industries face greater labor risk. 
To the best of my knowledge, the proposed empirical measure of labor mobility is the first to focus on the flexibility workers have to move in and out of a given industry. In particular, the measure is directly related to the degree of segmentation of an industry's labor market and is specific to the supply side of labor. Moreover, the measure is forward looking and therefore immune to ex-post shocks to the industry that could also affect realized stock returns.

\section{A.1. Data}

I obtain industry-level occupation data from the Occupational Employment Statistics (OES) program from the Bureau of Labor Statistics (BLS) from 1988 to 1995, and from 1997 to 2011. The dataset is based on surveys that track employment across occupations and industries and cover approximately 200,000 non-farm establishments in the United States every six months, not including self-employed workers. Before 1996, BLS collected data through three-year survey cycles, so that each industry was updated every three years. For these years, I use the same industry data for three years to ensure a continuous coverage of the full set of industries. After 1997, the frequency increased to annual cycles. There is no data available for 1996, so I use the 1997 data in 1996 . Before 1999, the dataset uses the OES taxonomy system with 258 broad occupation definitions, and the Standard Occupational Classification (SOC) system with 444 broad occupations afterwards. When needed, I bridge OES codes with SOC codes using the crosswalk provided by the National Crosswalk Service Center. Industries are classified using three-digit Standard Industrial Classification (SIC) codes until 2001 and four-digit North American Industry Classification System (NAICS) codes after that. ${ }^{10}$ I exclude from the sample industries denoted as "Not Elsewhere Classified" or "Miscellaneous" (SIC xx9 and NAICS xxx9), since firms in these industries are not likely to share a common workforce. The dataset covers 290 industries in 2010.

As previously discussed, the use of occupation dispersion as a proxy for labor mobility is justified by evidence that workers generally have less flexibility to switch occupations than to switch industries while remaining in the same occupation. This is a reasonable assumption for most

\footnotetext{
${ }^{10}$ Please see the Supplementary Appendix for more details about the OES survey methodology.
} 
occupations, but possibly not for occupations that do not require a significant level of specific preparation. For instance, workers in the highly concentrated occupation "waiters and waitresses" should have high mobility to move to a different industry and work in another low-barrier occupation (e.g., "cashiers"). I use the Job Zone index from the Occupational Information Network $\left(\mathrm{O}^{*} \mathrm{NET}\right)$ to classify occupations by their required level of specific preparation. I group all occupations described by O*NET as "occupations that need little or no preparation" (Job Zone one) into a single occupation, given the relative ease in which workers can move between them. ${ }^{11}$

\section{A.2. Methodology}

I construct the measure of labor mobility in two stages: first at the occupation level and then at the industry level. In the first stage, I estimate the inter-industry concentration of workers assigned to each occupation as a proxy for (the inverse of) their intrinsic flexibility to switch industries. The measure of concentration of workers in occupation $j$ is given by:

$$
\mathrm{CONC}_{j, t}=\left(\frac{\mathrm{emp}_{i, j, t}}{\sum_{i} \mathrm{emp}_{i, j, t}}\right)^{2}
$$

where $\mathrm{emp}_{i, j, t}$ is the number of workers assigned to occupation $j$ who are employed in industry $i$ at time $t$. For example, of the 91,610 "airline pilots and flight engineers" in 2010, 58,500 are found in the "scheduled air transportation" industry. The occupation is in fact highly concentrated $\left(\mathrm{CONC}_{j=\text { pilots }, t=10} \approx 0.5\right)$, which suggests that "airline pilots and flight engineers" have low interindustry mobility. The occupation "network and computer systems administrators" is found in 240 industries in 2010 and is highly dispersed $\left(\mathrm{CONC}_{j=\text { sys admin, } t=10} \approx 0.03\right)$, which suggests that these workers have relatively high flexibility to move across industries.

Table I presents a list of the most and least mobile occupations ranked by labor mobility in the year 2011. All occupations listed in the table have at least a few months of required specific

\footnotetext{
${ }^{11}$ The Job Zone index is based on the estimated number of years of formal education, on-the-job training and past experience required to undertake an occupation. A more detailed description of the Job Zone classification is provided in Appendix C
} 
preparation. The very low preparation occupations are grouped together, as discussed earlier, so are not shown in the table. Albeit not shown, these occupations are among the most mobile ones.

$$
<<\text { Table I here }>>
$$

In the second stage, I aggregate the occupation-level concentration measure, CONC, by industry, weighting by the wage expense associated with each occupation: ${ }^{12}$

$$
\mathrm{LM}_{i, t}=\left(\sum_{j} \mathrm{CONC}_{j, t} \times \frac{\mathrm{emp}_{i, j, t} \times \operatorname{wage}_{i, j, t}}{\sum_{j} \mathrm{emp}_{i, j, t} \mathrm{wage}_{i, j, t}}\right)^{-1},
$$

where wage $e_{i, j, t}$ is the mass of wages paid to workers in industry $i$ that are assigned to occupation $j$ at year $t$. Using wages in this stage is consistent with placing more weight on occupations with greater impact to cash flows. Finally, the measure in Equation (19) is standardized in order to simplify the interpretation of the results. ${ }^{13}$

Table II presents a list of the bottom 15 and top 15 industries ranked by labor mobility in the year 2011. The list only shows industries that are represented in the merged CRSP/Compustat dataset. A casual inspection of the table reveals that many manufacturing industries are represented among the most mobile. This is consistent with the high mobility of production occupations, some of which are among the most mobile as shown in Table I.

$$
<<\text { Table II here }>>
$$

\section{A.3. Validation}

This section presents evidence that supports the validity of the occupation-level measure of concentration, CONC. This measure, which is the fundamental building block of the industry-level measure LM, is designed to capture the level of inflexibility of workers to move across industries.

\footnotetext{
${ }^{12}$ BLS data does not contain occupation-level wage estimates for the years before 1997. Because of that, I use the wage expense weights estimates from 1997 in the previous years of the sample.

${ }^{13}$ Every year, the cross-sectional mean and standard deviation of the labor mobility measure are set to zero and one, respectively.
} 
We should therefore expect to observe relatively less significant flows of workers in high CONC, i.e., low mobility, occupations in response to industry shocks than of workers in low CONC, i.e., high mobility, occupations. I test this prediction using the following panel data regressions:

$$
\mathrm{OIEG}_{i, j, t}=\lambda_{0, i, j, t}+\lambda_{1} \mathrm{TFPG}_{i, t}+\lambda_{2} \mathrm{TFPG}_{i, t} \times \mathrm{HCONC}_{j, t}+\sum_{k>2} \lambda_{k} \operatorname{control}_{k, j, t}+\varepsilon_{i, j, t}
$$

where $\lambda_{0, i, j, t}$ denotes industry, occupation, and year fixed effects, OIEG $_{i, j, t}$ is the percentage growth in employment in the occupation-industry cluster $\left(\mathrm{emp}_{i, j}\right)$ from years $t-1$ to $t$, from the OES/BLS dataset, TFPG $_{i, t}$ is the change in the logarithm of total factor productivity that proxies for industry shocks, from the Capital, Labor, Energy, Materials, and Services (KLEMS) dataset,

provided by BLS, $\mathrm{HCONC}_{j, t}$ is a dummy for above median CONC, and $\left\{\operatorname{control}_{k, j, t}\right\}_{k=3,4}$ is a vector of occupation-level controls, from the OES/BLS dataset.

Table III reports the results of the regressions. The table reports a negative sign on the coefficient $\lambda_{2}$ in regression (20). This result is consistent with the hypothesis that high CONC workers respond less to industry shocks than low CONC workers. Models II to IV of the table show that this result is robust to controlling for alternative occupation characteristics that could also affect workers' responsiveness to shocks. Interestingly, workers in occupations that require high levels of specific preparation do not seem to respond less to industry shocks than other workers. This result is consistent with the evidence that workers tend to remain in their occupations when voluntarily changing industries. Workers in occupations with relatively high wages, or that require relatively high levels of specific preparation are only marginally less mobile.

$$
<<\text { Table III here }>>
$$

\section{B. Financial and Accounting Data}

Monthly common stock data is from the Center for Research in Security Prices (CRSP share code shrcd $=10$ or 11). Accounting information is from Standard and Poor's Compustat annual industrial files. The sample includes stocks listed on NYSE, AMEX, and NASDAQ, with available 
data in the CRSP/Compustat merged files. I follow the literature and exclude firms with primary standard industrial classifications between 4900 and 4999 (regulated) and between 6000 and 6999 (financials). I exclude firm-year observations with missing monthly returns in the year and/or with missing measures of size, book-to-market ratio, and leverage from the previous year. I exclude industry-year observations with fewer than two firms with valid stock data in the year. Firm-level accounting variables and size measures are Winsorized at the $1 \%$ level ( $0.5 \%$ in each extreme) in every sample year to reduce the influence of possible outliers. For the same reason, I exclude from the sample the lowest $20^{\text {th }}$ size quantile, i.e., $5 \%$, of the sample of firms to avoid anomalies driven by micro-cap firms, as discussed in Fama and French (2008).

Size is defined as the market value of equity (Compustat fields price, prc, times shares outstanding, shrout) at the end of June. Book value is defined as shareholders' equity (Compustat SEQ) divided by the market value of equity. Leverage ratios are calculated as the book value of debt adjusted for cash holdings, as reported in Compustat, divided by the assets (book-valued leverage ratio), or divided by the sum of market value of equity and book value of debt (market-valued leverage ratio). Labor intensity is proxied by the logarithm of the ratio of the number of employees divided by PPE.

\section{Summary Statistics of Portfolios of Firms Sorted on Labor Mobility}

Table IV reports the time-series averages of median characteristics of firms sorted on labor mobility (LM). Panel A of the table describes labor related characteristics and Panel B describes financial and accounting characteristics across the LM portfolios. The table shows that high LM firms are more labor intensive and rely more on skilled workers than low LM firms, although the level of median wages paid does not seem to be different across the portfolios. High mobility firms have lower volatility of wages paid than low mobility of firms, which suggests that high mobility workers are less exposed to risk than their low mobility peers.

High LM firms have lower median size and leverage than low LM firms. Note that these 
findings are consistent with the hypothesis that firms in the $H$ portfolio are riskier than those in the $L$ portfolio. Based on Berk's (1995) argument, if firms in the $H$ portfolio have higher discount rates, then, all else equal, they should also have lower valuations than those in the $L$ portfolio. Similarly, according to a standard trade-off theory argument, such as the one discussed in Leland (1994), we should also expect lower leverage ratios from firms in the $H$ portfolio given their riskier cash flows. Also consistent with the positive link between firm risk and LM is the finding that a measure of the sensitivity of operating cash flows to industry shocks, i.e., operating leverage, is monotonically increasing across the LM portfolios. The table also shows a positive relationship between loadings on systematic risk and LM: the median conditional market and size risk factor betas are higher in the $H$ portfolio than in the $L$ portfolio, although the median value risk factor betas are fairly flat across quintiles. The median book-to-market is slightly lower in high mobility firms, possibly due to the higher labor intensity of these firms, which is not captured by the book value of equity.

The table shows that the median industry concentration measure, constructed as in Hou and Robinson (2006), does not seem related to LM. Finally, the table also reports the median Organizational Capital (OC), constructed as in Eisfeldt and Papanikolaou (2012), across the LM portfolios. Firms in portfolio $H$ have higher median levels of OC than those in portfolio $L$, and the effect is fairly monotonic across LM portfolios. ${ }^{14}$

$$
<<\text { Table IV here }>>
$$

I next investigate the relation between the measure of labor mobility and firms' characteristics using panel data regressions with year effects. Table $\mathrm{V}$ shows estimates of panel data regressions with year effects of LM on median industry characteristics. The equation tested is:

$$
\mathrm{LM}_{i, t}=c_{0, t}+\sum_{k} c_{k} \mathrm{CARA}_{k, i, t}+\varepsilon_{i, t}
$$

\footnotetext{
${ }^{14}$ The Supplementary Appendix presents evidence that suggests that the positive relationship between these measures is related to the properties of labor employed across firms sorted on LM and OC. I find that high OC firms tend to rely more on highly mobile sales and administrative workers than low OC firms. Similarly, high LM firms tend to have more workers in managerial occupations-generally associated with high OC levels-than low LM firms.
} 
where $\mathrm{CARA}_{k, i, t}$ is the median firm characteristic $k$ of industry $i$ at time $t$ and $c_{0, t}$ denotes time- $t$ fixed effects. The resulting coefficients can be interpreted as correlations between LM and median industry characteristics. The table confirms that LM is positively associated with the measure of operating leverage. This result is consistent with the labor-induced form of operating leverage due to labor mobility, although LM is in the left side of the regressions. Labor mobility is negatively related with unionization levels, consistent with the hypothesis that immobile workers would benefit more from forming unions given their greater exposure to labor risk.

$$
<<\text { Table Vhere }>>
$$

\section{Labor Mobility and Operating Leverage}

The model predicts that firms in industries with high labor mobility have operating profits more sensitive to industry shocks. To investigate this prediction, I construct a measure of operating leverage at the industry level using data from the Capital, Labor, Energy, Materials, and Services (KLEMS) dataset, provided by BLS. The dataset groups industries into 59 broad groups. ${ }^{15}$ Operating leverage for industry $i$ is defined as the slope of total factor productivity growth of the following time-series regression:

$$
\mathrm{CPG}_{i, t}=\lambda_{i, 0}+\lambda_{i, 1} \mathrm{TFPG}_{i, t}+\varepsilon_{i, t}
$$

where $\mathrm{CPG}_{i, t}$ is the change in the logarithm of capital payments (from Table 4.2a of KLEMS database) and $\mathrm{TFPG}_{i, t}$ is the change in the logarithm of total factor productivity (from Tables 1$9 \mathrm{~b}$ and 1-10a of KLEMS manufacturing and non-manufacturing databases, respectively), all from the BLS. Next, I run the following panel data regressions to investigate the relationship between

\footnotetext{
${ }^{15} \mathrm{~A}$ list of the broad industry groups is provided in Table 1 of the Supplementary Appendix.
} 
operating leverage and LM:

$$
\lambda_{i, 1}=c_{0, t}+c_{1} \mathrm{LM}_{i, t}+\sum_{k \geq 2} c_{k} \mathrm{CARA}_{k, i, t}+\varepsilon_{i, t}
$$

where $\lambda_{i, 1}$ is operating leverage, defined in regression (22), $c_{0, t}$ denotes time- $t$ fixed effects, $\mathrm{LM}_{i, t}$ the measure of LM for industry $i$ at time $t$, and $\mathrm{CARA}_{k, i, t}$ is the median firm characteristic $k$ for industry $i$ at time $t$.

Table VI reports results of the regressions (23). The table shows that operating leverage is positively associated with LM and not explained by median firm characteristics. This result supports the model's prediction that the labor's flexibility to move in response to shocks leads to an amplification of shocks to the owners of capital. The table confirms the finding presented by Chen et al. (2011) that unionized workers increase the level of operating leverage of their employers. The table also shows that operating leverage is positively related to book-to-market ratios, which is consistent with the mechanism proposed by Carlson et al. (2004) that links together operating leverage and the value premium.

$$
<<\text { Table VI here }>>
$$

To further examine the relation between the sensitivity of operating cash flows and LM, Table VII reports results of the following regressions:

$$
\mathrm{CPG}_{i, t}=\lambda_{0, i, t}+\lambda_{1} \mathrm{TFPG}_{i, t}+\lambda_{2} \mathrm{LM}_{i, t}+\lambda_{3} \mathrm{LM}_{i, t} \times \mathrm{TFPG}_{i, t}+\sum_{k>3} \lambda_{k} \mathrm{CON}_{k, i, t}+\varepsilon_{i, t}
$$

where $\lambda_{0, i, t}$ denotes industry and year fixed effects and $\left\{\mathrm{CON}_{k, i, t}\right\}_{k=4,5,6}$ is a vector of industrylevel controls. An advantage of the specification of regression (24) over the one used in regression (23) is that the former does not require a preliminary pass to construct a measure of operating leverage. The table shows that the cross effect between TFP and LM is positive (i.e., $\lambda_{3}>0$ ). This result confirms the findings presented in Table VI.

$$
<<\text { Table VII here }>>
$$




\section{E. Labor Mobility and Expected Returns}

This session presents supporting evidence for the model's implications on expected returns. The model predicts a positive cross-sectional relation between labor mobility and expected returns through loadings on systematic risk i.e., betas. The challenge for an empirical investigation is that neither expected returns nor systematic risk is observable. To address this challenge, I use two complementary broad strategies. The first strategy is to estimate expected returns directly, without relying on assumptions about the source of systematic risk in the economy. Under this strategy, I find evidence for a positive relation between LM and two different proxies for expected returns: expost realized stock returns and measures of implied cost of capital (ICC). The second strategy is to estimate expected returns using proxies for systematic risk suggested by the literature. Following this approach, I find support for a positive relation between LM and CAPM betas, and between the return spreads of a high-minus-low labor mobility portfolio and the returns of traditional risk factors.

\section{E.1. Using Estimates for Expected Returns}

This section investigates whether realized asset returns of portfolios of stocks sorted on the measure of labor mobility are increasing in LM. The portfolio construction procedure is the following: For each year of the sample, I assign the measure of LM lagged one year to individual stocks by industry code (NAICS when available, otherwise SIC). I then sort stocks on LM and assign them into five quintile LM portfolios. ${ }^{16}$ I construct series of equally-weighted and value-weighted monthly returns for each LM portfolio. Value-weighted stocks are rebalanced every month.

I consider two main types of asset returns: equity returns and unlevered equity returns. While equity returns provide results that are easier to compare to those in the literature, unlevered asset returns relate more directly to the model's predictions of the labor mobility effect on firm risk. A possible negative endogenous relation between firm risk and leverage ratios would imply that part

\footnotetext{
${ }^{16}$ Given that the LM measure is at the industry level, all stocks in a given industry are assigned to the quintile most represented by the industry.
} 
of the effect of labor mobility on equity risk is offset by lower leverage ratios. Unlevered stock returns are constructed according to the following:

$$
r_{f, y, m}^{\mathrm{u}}=r_{y, m}^{\mathrm{T}}+\left(r_{f, y, m}-r_{y, m}^{\mathrm{T}}\right)\left(1-\mathrm{lev}_{f, y-1}\right),
$$

where $r_{f, y, m}$ denotes the monthly stock return of firm $f$ over month $m$ of year $y, r_{y, m}^{\mathrm{T}}$ denotes the one-month Treasury bill rate at month $m$ of year $y$, and $\operatorname{lev}_{f, y-1}$ denotes the leverage ratio measure, defined as book value of debt over the sum of book value of debt plus the market value of equity at the end of year $y-1$ for firm $f$.

I also construct a measure of stock returns adjusted for firm characteristics known to be ex-ante predictors of stock returns in the cross-section. I follow the methodology in Daniel, Grinblatt, Titman, and Wermers (1997) and construct 125 benchmark portfolios, sequentially triple-sorted on the previous year's size, book-to-market ratio, and past stock performance. The procedure uses NYSE-based breakpoints in the triple sorting and constructs value-weighted portfolios to avoid overweighting very small stocks. I then subtract the returns of the benchmark portfolios from each constituent firm's stock returns. An adjusted return of zero for a given stock indicates that the return is fully explained by the firms' size, book-to-market ratio, and past performance.

Table VIII presents average post-ranking returns of portfolios of firms sorted on labor mobility. The table supports the theoretical prediction of a positive relation between LM and expected asset returns. Results are presented for excess stock returns over treasury bills and for unlevered stock returns. Each of these types of returns is further presented adjusted for size, book-to-market, and past returns, according to the methodology in Daniel et al. (1997). The H-L portfolio is a zero net investment, monthly-rebalanced portfolio, with a long position in stocks in the highest mobility quintile and a short position in stocks in the lowest mobility quintile. The H-L portfolio earns economically significant excess monthly stock returns of $0.43 \%$. Even though the sample period considered is relatively short, $t$-tests using Newey-West standard errors with one lag confirm that this spread is significantly different from zero. 


$$
<<\text { Table VIII here }>>
$$

What is the economic significance of the predictive power of the measure LM on the cross section of returns? To examine this question, Table IX reports results of panel data regressions with year effects of annual returns on LM. I include firm size, book-to-market ratios, one-yearlagged stock returns, CAPM market beta, labor intensity, and leverage ratios in the regressions, to control for other characteristics known to explain expected returns. Across all specifications, the average slope of returns on the measure of LM is positive and significantly different from zero, and is relatively unaffected by firms' characteristics. The slopes range from $1.67 \%$ to $2.16 \%$ per year. Since LM is standardized, these slopes can be interpreted as the additional return premium associated with a one-standard-deviation increase in labor mobility.

$$
<<\text { Table IX here }>>
$$

Next, I investigate the link between LM and measures of implied cost of capital (ICC). These measures are used as additional alternatives to the use of realized returns as a proxy for expected returns. An advantage of measures of ICC over those based on realized returns is that the former are less sensitive to the quality of stock return data, while also being agnostic about the source of systematic risk in the economy. I use three alternative ICC measures in the regressions. The first, $G L S$, is the measure proposed by Gebhardt, Lee, and Swaminathan (2002) and employs analyst earning forecasts. The other two measures, $W Z$ and $H V D Z$, proposed by $\mathrm{Wu}$ and Zhang (2008) and by Hou, van Dijk, and Zhang (2012), respectively, are based on regressions to forecast ROE (WZ) and level of earnings (HVDZ).

Table X reports results of panel data regressions of ICC measures on LM, with firm controls and year effects. Panel A of the table reports results of regressions at the industry level, in which the dependent variables are median ICC measures. Panel B of the table reports results of regressions at the firm level. Overall, I find a positive relation between ICC and LM.

$$
<<\text { Table X here }>>
$$




\section{E.2. Using Estimates for Systematic Risk}

The previous section investigates the relation between LM and expected returns by using realized returns and implied cost of capital measures as proxies for expected returns. This section confirms this finding by establishing a positive link between LM and loadings on systematic risk, which, according to the model, ultimately determine expected returns.

Table XI reports estimates of the unconditional (Panel A) and conditional (Panel B) CAPM models across portfolios of stocks of firms sorted on the measure LM. An inspection of the alphas in Panel A reveals that the unconditional CAPM is unable to price portfolios of high mobility stocks. In particular, market betas are almost flat across the LM portfolios. ${ }^{17}$

The unconditional tests shown in Panel A of Table XI assume that betas are constant over time. I relax this assumption in Panel B and test a conditional version of the CAPM following the methodology described in Lewellen and Nagel (2006). I estimate market betas every year using monthly returns, and find that the average conditional betas are increasing across the LM portfolio. The time-series averages of the conditional betas of these portfolios are increasing in LM, while those of conditional alphas are not significantly different from zero. ${ }^{18}$ The relative success of the conditional CAPM over the unconditional CAPM is not unique to sorts on LM: during the same sample period of 1989-2011, the unconditional CAPM fails to price stocks sorted on market capitalization, while the conditional CAPM succeeds. ${ }^{19}$

$$
<<\text { Table XI here }>>
$$

Why are conditional betas across the labor mobility portfolios changing over time? One possible explanation is that changes in labor market conditions affect the additional systematic risk loading related to a mobile workforce. In particular, we should expect that the effect labor mobility on risk firm risk should be greater when conditions are more favorable for workers to move.

\footnotetext{
${ }^{17}$ Table 3 in the Supplementary Appendix shows that the Fama and French (1993) three-factor model and Carhart (1997) four-factor models are also unable to price portfolios of stock sorted on LM.

${ }^{18}$ Table 4 in the Supplementary Appendix confirms this result in regressions that control for size and book to market ratios.

${ }^{19}$ See Table 5 of the Supplementary Appendix for details.
} 
When net job creation in the economy is high, mobile workers have arguably more outside options to move to. Figure 2 shows evidence for a significant positive relation between net job creation in the economy and the conditional betas of the high minus low LM portfolio. Quarterly net job creation estimates used in the figure are described in Davis, Haltiwanger, and Schuh (1998) and obtained from Steven Davis' website. Conditional betas of the LM H-L portfolios are estimated every quarter with daily returns, and corrected for non-synchronous trading following the methodology described in Lewellen and Nagel (2006).

$$
<<\text { Figure } 2 \text { here }>>
$$

Labor mobility amplifies a firm's exposure to systematic risk. We should therefore expect that the return spread between high and low labor mobility firms should widen when systematic risk increases. I investigate whether the labor mobility premium is related to standard risk factors and macro variables related to the business cycle. I construct a time-series of the monthly return of the zero equally-weighted portfolio long high LM firms and short low LM firms (i.e., portfolio H-L, presented in Table VIII). I then run time-series regressions of monthly labor mobility premium on different risk factor's premia and on macro-variables that proxy for the business cycle.

Table XII reports the regression results. The intercept of the first column represents the unconditional average LM premium over the sample period, which was 43 basis points per month, or around $5.3 \%$ per year. The second to fifth columns include risk factors. The risk factors used are the market excess returns, the size and book-to-market factors-mimicking returns described in Fama and French (1993), and the momentum factor-mimicking returns obtained from Kenneth French's website. None of these standard risk factors fully explains the LM premium. The intercept in these repressions with risk factors is statistically and economically significant and similar in magnitude to the unconditional average LM return spread. The LM return spread has a negative loading on the HML risk factor. Although this result seems to contradict the operating leverage mechanism, it is consistent with the negative loading of labor risk embedded in mobile firms predicted by the model. Fama and French (1996) argue that the HML premia is related to distress risk, which ultimately is 
a state-variable that, according to the authors, should directly affect human capital risk. ${ }^{20}$

The remaining columns of Table XII indicate that the LM spread is weakly countercyclical, as indicated by the negative, although statistically insignificant, slopes of LM on GDP and lagged GDP growth rates, monthly rate of inflation, and unemployment rate. The variables are demeaned so that the level of the intercept can be interpreted as the unexplained portion of the labor mobility return spread. The results presented in the table therefore show that the LM return spread is not explained by macro-variables that proxy for economic conditions.

$$
<<\text { Table XII here }>>
$$

\section{Conclusion}

This work suggests that labor mobility, i.e., the flexibility workers have to move across industries, is an observable industry characteristic with new and promising implications for asset pricing. I develop a production-based model of an industry in which labor mobility subjects firm owners to additional labor supply fluctuations that amply the sensitivity of operating cash flows to exogenous shocks. In this sense, labor mobility translates into a labor-induced form of operating leverage, which leads to higher stock returns.

There are no existing measures at the firm or industry levels of the flexibility of workers to leave. In order to investigate the implications of the model, I construct a simple empirical measure for labor mobility, consistent with the theory, based on the level of inter-industry dispersion of workers across occupations. The measure is motivated by evidence that labor mobility is mainly determined by the level of specificity of labor skills, which are captured by occupations.

I present novel empirical evidence that supports the main predictions of the model. I find that the return spread between stocks in industries with high mobility and those of industries with low labor mobility is positive and economically significant even after controlling for characteristics

\footnotetext{
${ }^{20}$ Interestingly, there seems to be negative relation between the LM spread and distress risk, as shown in Table 7 of the Supplementary Appendix. The table shows that a two factor model that includes the LM return spread is more effective than the CAPM at pricing portfolios sorted on measures of distress risk.
} 
known by the literature to explain the cross-section of returns. I also find that the measure of labor mobility is positively related to a measure of operating leverage and to conditional CAPM betas. These findings are confirmed across a number of different specifications. 


\section{References}

Bardhan, Ashok, and John Tang, 2010, What Kind of Job is Safer? A Note on Occupational Vulnerability, The B.E. Journal of Economic Analysis \& Policy 10.

Basu, Sanjoy, 1983, The relationship between earnings' yield, market value and return for NYSE common stocks: Further evidence, Journal of Financial Economics 12, 129-156.

Bazdresch, Santiago, Frederico Belo, and Xiaoji Lin, 2009, Labor Hiring, Investment and Stock Return Predictability in the Cross Section, working paper.

Becker, Gary S., 1964, Human capital, Columbia University Press, New York, NY.

Berk, Jonathan B., 1995, A critique of size-related anomalies, Review of Financial Studies 8, 275 -286.

Berk, Jonathan B., Richard C. Green, and Vasant Naik, 1999, Optimal Investment, Growth Options, and Security Returns, Journal of Finance 54, 1553-1607.

Bhandari, Laxmi Chand, 1988, Debt/equity ratio and expected common stock returns: Empirical evidence, Journal of Finance 43, 507-528.

Carhart, Mark M., 1997, On Persistence in Mutual Fund Performance, Journal of Finance 52, 57-82.

Carlson, Murray, Adlai Fisher, and Ron Giammarino, 2004, Corporate Investment and Asset Price Dynamics: Implications for the Cross-Section of Returns, Journal of Finance 59, 2577-2603.

Chan, K. C., and Nai-Fu Chen, 1991, Structural and Return Characteristics of Small and Large Firms, Journal of Finance 46, 1467-1484.

Chen, Huafeng, Marcin Kacperczyk, and Hernan Ortiz-Molina, 2011, Labor Unions, Operating Flexibility, and the Cost of Equity, Journal of Financial and Quantitative Analysis 46, 25-58.

Cochrane, John H., 1991, Production-Based Asset Pricing and the Link Between Stock Returns and Economic Fluctuations, Journal of Finance 46, 209-237.

Daniel, Kent, Mark Grinblatt, Sheridan Titman, and Russ Wermers, 1997, Measuring Mutual Fund Performance with Characteristic-Based Benchmarks, Journal of Finance 52, 1035-1058.

Danthine, Jean-Pierre, and John B. Donaldson, 2002, Labor Relations and Asset Returns, Review of Economic Studies 69, 41-64.

Davis, Steven J., and John Haltiwanger, 2001, Sectoral job creation and destruction responses to oil price changes, Journal of Monetary Economics 48, 465-512. 
Davis, Steven J., John Haltiwanger, and Scott Schuh, 1998, Job creation and destruction. (The MIT Press, Cambridge, MA).

Eisfeldt, Andrea L., and Dimitris Papanikolaou, 2012, Organization Capital and the Cross-Section of Expected Returns, Journal of Finance, forthcoming.

Fama, Eugene F., and Kenneth R. French, 1992, The Cross-Section of Expected Stock Returns, Journal of Finance 47, 427-465.

Fama, Eugene F., and Kenneth R. French, 1993, Common risk factors in the returns on stocks and bonds, Journal of Financial Economics 33, 3-56.

Fama, Eugene F., and Kenneth R. French, 1996, Multifactor Explanations of Asset Pricing Anomalies, The Journal of Finance 51, 55-84.

Fama, Eugene F., and Kenneth R. French, 2008, Dissecting Anomalies, Journal of Finance 63, 1653-1678.

Gebhardt, William R., Charles M. C. Lee, and Bhaskaran Swaminathan, 2002, Toward an Implied Cost of Capital, Journal of Accounting Research 39, 135-176.

Gourio, F., 2007, Labor Leverage, Firms Heterogeneous Sensitivities to the Business Cycle, and the CrossSection of Expected Returns, working paper.

Griffin, John M., and Michael L. Lemmon, 2002, Book-to-Market Equity, Distress Risk, and Stock Returns, Journal of Finance 57, 2317-2336.

Grossman, Gene M, and Carl Shapiro, 1982, A Theory of Factor Mobility, Journal of Political Economy 90, 1054-1069.

Hou, Kewei, Mathijs A. Van Dijk, and Yinglei Zhang, 2012, The Implied Cost of Capital: A New Approach, Journal of Accounting and Economics, forthcoming.

Hou, Kewei, and David T. Robinson, 2006, Industry Concentration and Average Stock Returns, Journal of Finance 61, 1927-1956.

Jagannathan, Ravi, and Zhenyu Wang, 1996, The Conditional CAPM and the Cross-Section of Expected Returns, Journal of Finance 51, 3-53.

Johnson, William R., 1979, The Demand for General and Specific Education with Occupational Mobility, Review of Economic Studies 46, 695-705.

Kambourov, Gueorgui, and Iourii Manovskii, 2009a, Occupational Mobility and Wage Inequality, The Review of Economic Studies 76, 731-759. 
Kambourov, Gueorgui, and Iourii Manovskii, 2009b, Occupational Specificity of Human Capital, International Economic Review 50, 63-115.

Kuehn, Lars-Alexander, Nicolas Petrosky-Nadeau, and Lu Zhang, 2012, An Equilibrium Asset Pricing Model with Labor Market Search, working paper.

Leland, Hayne E., 1994, Corporate Debt Value, Bond Covenants, and Optimal Capital Structure, Journal of Finance 49, 1213-1252.

Lewellen, Jonathan, and Stefan Nagel, 2006, The conditional CAPM does not explain asset-pricing anomalies, Journal of Financial Economics 82, 289-314.

Lustig, Hanno N., Chad Syverson, and Stijn Van Nieuwerburgh, 2011, Technological Change and the Growing Inequality in Managerial Compensation, Journal of Financial Economics 99, 601-627.

Merz, Monika, and Eran Yashiv, 2007, Labor and the Market Value of the Firm, American Economic Review 97, 1419-1431.

Neal, Derek, 1995, Industry-Specific Human Capital: Evidence from Displaced Workers, Journal of Labor Economics 13, 653-677.

Parent, Daniel, 2000, Industry-specific capital and the wage profile: Evidence from the national longitudinal survey of youth and the panel study of income dynamics, Journal of Labor Economics 18, 306-323.

Shaw, Kathryn L., 1984, A Formulation of the Earnings Function Using the Concept of Occupational Investment, The Journal of Human Resources 19.

Shaw, Kathryn L., 1987, Occupational Change, Employer Change, and the Transferability of Skills, Southern Economic Journal 53, 702-719.

Sullivan, Paul, 2010, Empirical evidence on occupation and industry specific human capital, Labour Economics $17,567-580$.

Tristao, I. M., 2007, Occupational Employment Risk and Its Consequences for Unemployment Duration and Wages, working paper.

Willis, R.J., 1985, Wage determinants: A survey and reinterpretation of human capital earnings functions. (Economics Research Center/NORC).

Wu, Jin, and Lu Zhang, 2008, Do Anomalies Exist Ex Ante?, working paper.

Zhang, Lu, 2005, The Value Premium, Journal of Finance 60, 67-103. 


\section{Appendix}

\section{A. Derivation of the Value of the Firm}

Proof. I omit time subscripts in what follows. Assume that there exists a traded asset that pays a continuous stream of dividends identical to the operating profits of the industry. The discounted value of a portfolio of a traded asset that continually reinvests its dividends in the asset is a martingale:

$$
0=\Lambda \Pi^{*} d t+\mathrm{E}\left[d\left(\Lambda V\left(\Pi^{*}\right)\right)\right]
$$

Let $V=A v(x)$. Applying Ito's Lemma to equation (A1) and simplifying leads to:

$$
0=(1-\alpha) x^{\frac{\alpha \delta}{1-\alpha \delta}}+c_{0} v(x)+c_{1} x v^{\prime}(x)+c_{2} x^{2} v^{\prime \prime}(x),
$$

where $c_{0}=-r-\eta \sigma_{\mathrm{A}}^{\lambda}$

$$
\begin{aligned}
& c_{1}=\left(\sigma_{\mathrm{A}}^{\varepsilon}\right)^{2}+\left(\sigma_{\mathrm{A}}^{\lambda}\right)^{2}+\left(\sigma_{\mathrm{G}}^{v}\right)^{2}+\left(\sigma_{\mathrm{G}}^{\lambda}\right)^{2}-2 \sigma_{\mathrm{A}}^{\lambda} \sigma_{\mathrm{G}}^{\lambda}+\eta\left(\sigma_{\mathrm{G}}^{\lambda}-\sigma_{\mathrm{A}}^{\lambda}\right) \\
& c_{2}=\frac{1}{2}\left(\left(\sigma_{\mathrm{A}}^{\varepsilon}\right)^{2}+\left(\sigma_{\mathrm{G}}^{v}\right)^{2}+\left(\sigma_{\mathrm{A}}^{\lambda}-\sigma_{\mathrm{G}}^{\lambda}\right)^{2}\right) .
\end{aligned}
$$

Equation (A2) has a known solution given by $V=A v(x)=\frac{\Pi^{*}}{\alpha \delta\left(\left(c_{2}-c_{1}\right)+\left(c_{1}-2 c_{2}\right) \alpha \delta\right) /(1-\alpha \delta)^{2}-c_{0}}$, which simplifies to Equation (15).

\section{B. Proof of Lemma 1}

Proof. I omit time subscripts in what follows. I show below that, for sufficiently small $\sigma$, the assumption that the concentration of occupations increases with industry-specialization, i.e., $\frac{d \gamma_{j}}{d j}<$ 0 , implies that the average dispersion of occupations in the industry is increasing in labor mobility, i.e., $\frac{d\left(\mathrm{E}\left[\Gamma_{i}\right]\right)^{-1}}{d \delta}>0$. From $\frac{d \gamma_{j}}{d j}<0$ and from the mean value theorem for integration, we have that $\mathrm{E}\left[\gamma^{*}-\Gamma_{i}^{*}\right]<0$, since $1>\Gamma_{i}=\int_{0}^{j^{*}} \gamma_{j} d j / j^{*}>\gamma^{*}>0$, where $\left.\gamma^{*} \equiv \gamma_{j}\right|_{j=j^{*}}$. From the assumption 
$\frac{d \gamma_{j}}{d j}<0$ and fact that $\frac{d j^{*}}{d z}=x \frac{\delta}{1-\alpha \delta}>0$, we have $\frac{d \gamma^{*}}{d j^{*}}<0$, and therefore $\mathrm{E}\left[\frac{d \gamma^{*}}{d z}\right]=\mathrm{E}\left[\frac{d \gamma^{*}}{d j^{*}} \frac{d j^{*}}{d z}\right]<0$. From the definition of $\Gamma_{i}$ we have:

$$
\begin{aligned}
\frac{d \mathrm{E}\left[\Gamma_{i}^{*}\right]}{d \delta} & =\mathrm{E}\left[\frac{d \Gamma_{i}^{*}}{d \delta}\right] \\
& =\mathrm{E}\left[\frac{1}{j^{*}} \frac{d j^{*}}{d \delta}\left(\gamma^{*}-\Gamma_{i}^{*}\right)\right] \\
& =\mathrm{E}\left[\frac{1}{\delta}\left(\gamma^{*}-\Gamma_{i}^{*}\right)+\frac{\alpha}{(1-\alpha \delta)^{2}} z\left(\gamma^{*}-\Gamma_{i}^{*}\right)\right] \\
& =\frac{1}{\delta} \mathrm{E}\left[\gamma^{*}-\Gamma_{i}^{*}\right]+\frac{\alpha}{(1-\alpha \delta)^{2}} \mathrm{E}\left[z\left(\gamma^{*}-\Gamma_{i}^{*}\right)\right] \\
& =\left(\frac{1}{\delta}-\frac{\alpha \sigma^{2}}{(1-\alpha \delta)^{3}}\right) \mathrm{E}\left[\gamma^{*}-\Gamma_{i}^{*}\right]+\left(\frac{\alpha \sigma^{2}}{(1-\alpha \delta)^{2}}\right) \mathrm{E}\left[\frac{d \gamma^{*}}{d z}\right]
\end{aligned}
$$

The second equally uses the fact that the industry is small relative to the economy, so that $\frac{d \gamma_{j}}{d \delta}=0$, and the last equality follows from the application of Stein's Lemma. Therefore, for sufficiently small $\sigma^{2}$, such that $\left(\frac{1}{\delta}-\frac{\alpha \sigma^{2}}{(1-\alpha \delta)^{3}}\right) \geq 0$, we have: ${ }^{21}$

$$
\frac{\partial\left(\mathrm{E}\left[\Gamma_{i}\right]\right)^{-1}}{\partial \delta}=-\frac{1}{\mathrm{E}\left[\Gamma_{i}\right]^{2}} \frac{\partial \mathrm{E}\left[\Gamma_{i}\right]}{\partial \delta}>0
$$

\section{Job Zone Descriptions}

I use Job Zone groups, obtained from The Occupational Information Network (O*NET), as a proxy for occupation-specific preparation. The following descriptions of the Job Zone groups are quoted from O*NET's website: ${ }^{22}$

JOB ZONE ONE: Little or No Preparation Needed

Education: Some of these occupations may require a high school diploma or GED certificate.

Related Experience: Little or no previous work-related skill, knowledge, or experience is needed for these occupations. For example, a person can become a waiter or waitress even if he/she has never worked before.

\footnotetext{
${ }^{21}$ Note that $\left(\frac{1}{\delta}-\frac{\alpha \sigma^{2}}{(1-\alpha \delta)^{3}}\right) \geq 0$ is a sufficient condition that can be weakened or eliminated by defining an appropriate functional form for $\gamma$.

${ }^{22}$ Retrieved May 25, 2012, from http://www.onetonline.org/help/online/zones.
} 
Job Training: Employees in these occupations need anywhere from a few days to a few months of training. Usually, an experienced worker could show you how to do the job.

Job Zone Examples: These occupations involve following instructions and helping others. Examples include taxi drivers, amusement and recreation attendants, counter and rental clerks, construction laborers, continuous mining machine operators, and waiters/waitresses.

JOB ZONE TWO: Some Preparation Needed

Education: These occupations usually require a high school diploma.

Related Experience: Some previous work-related skill, knowledge, or experience is usually needed. For example, a teller would benefit from experience working directly with the public.

Job Training: Employees in these occupations need anywhere from a few months to one year of working with experienced employees. A recognized apprenticeship program may be associated with these occupations.

Job Zone Examples: These occupations often involve using your knowledge and skills to help others. Examples include sheet metal workers, forest fire fighters, customer service representatives, physical therapist aides, salespersons (retail), and tellers.

JOB ZONE THREE: Medium Preparation Needed

Education: Most occupations in this zone require training in vocational schools, related on-the-job experience, or an associate's degree.

Related Experience: Previous work-related skill, knowledge, or experience is required for these occupations. For example, an electrician must have completed three or four years of apprenticeship or several years of vocational training, and often must have passed a licensing exam, in order to perform the job.

Job Training: Employees in these occupations usually need one or two years of training involving both onthe-job experience and informal training with experienced workers. A recognized apprenticeship program may be associated with these occupations.

Job Zone Examples: These occupations usually involve using communication and organizational skills to coordinate, supervise, manage, or train others to accomplish goals. Examples include food service managers, electricians, agricultural technicians, legal secretaries, interviewers, and insurance sales agents.

JOB ZONE FOUR: Considerable Preparation Needed

Education: Most of these occupations require a four-year bachelor's degree, but some do not.

Related Experience: A considerable amount of work-related skill, knowledge, or experience is needed for these occupations. For example, an accountant must complete four years of college and work for several years in accounting to be considered qualified.

Job Training: Employees in these occupations usually need several years of work-related experience, on-thejob training, and/or vocational training.

Job Zone Examples: Many of these occupations involve coordinating, supervising, managing, or training others. Examples include accountants, sales managers, database administrators, teachers, chemists, environmental engineers, criminal investigators, and special agents.

JOB ZONE FIVE: Extensive Preparation Needed

Education: Most of these occupations require graduate school. For example, they may require a master's degree, and some require a Ph.D., M.D., or J.D. (law degree). 
Related Experience: Extensive skill, knowledge, and experience are needed for these occupations. Many require more than five years of experience. For example, surgeons must complete four years of college and an additional five to seven years of specialized medical training to be able to do their job.

Job Training: Employees may need some on-the-job training, but most of these occupations assume that the person will already have the required skills, knowledge, work-related experience, and/or training.

Job Zone Examples: These occupations often involve coordinating, training, supervising, or managing the activities of others to accomplish goals. Very advanced communication and organizational skills are required. Examples include librarians, lawyers, aerospace engineers, wildlife biologists, school psychologists, surgeons, treasurers, and controllers. 


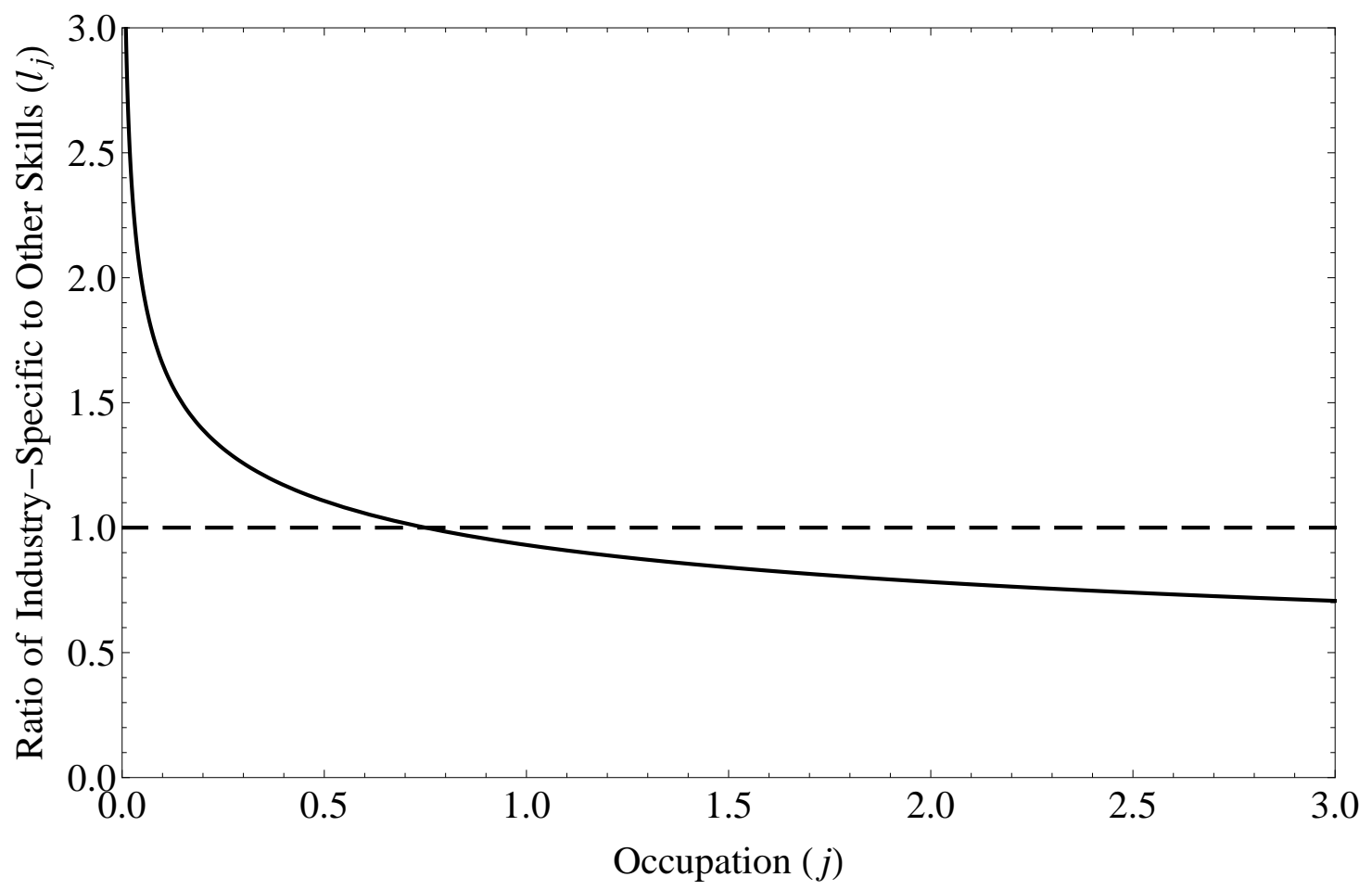

Figure 1. Labor Mobility and Level of Labor Market Segmentation This plot shows the ratio of industry-specific skills to skills useful outside the industry $\left(l_{j}\right)$ across occupations in the model. The dashed line represents an immobile industry $(\delta \rightarrow 0)$ and the solid line represents a mobile industry $(\delta=0.75)$. $\delta$ captures the degree of integration of the labor supply in the industry to that of the rest of the economy and is related to the degree of similarity between an industry specialist (worker in a "low-j" occupation) and a generalist (worker in a "high-j" occupation). 


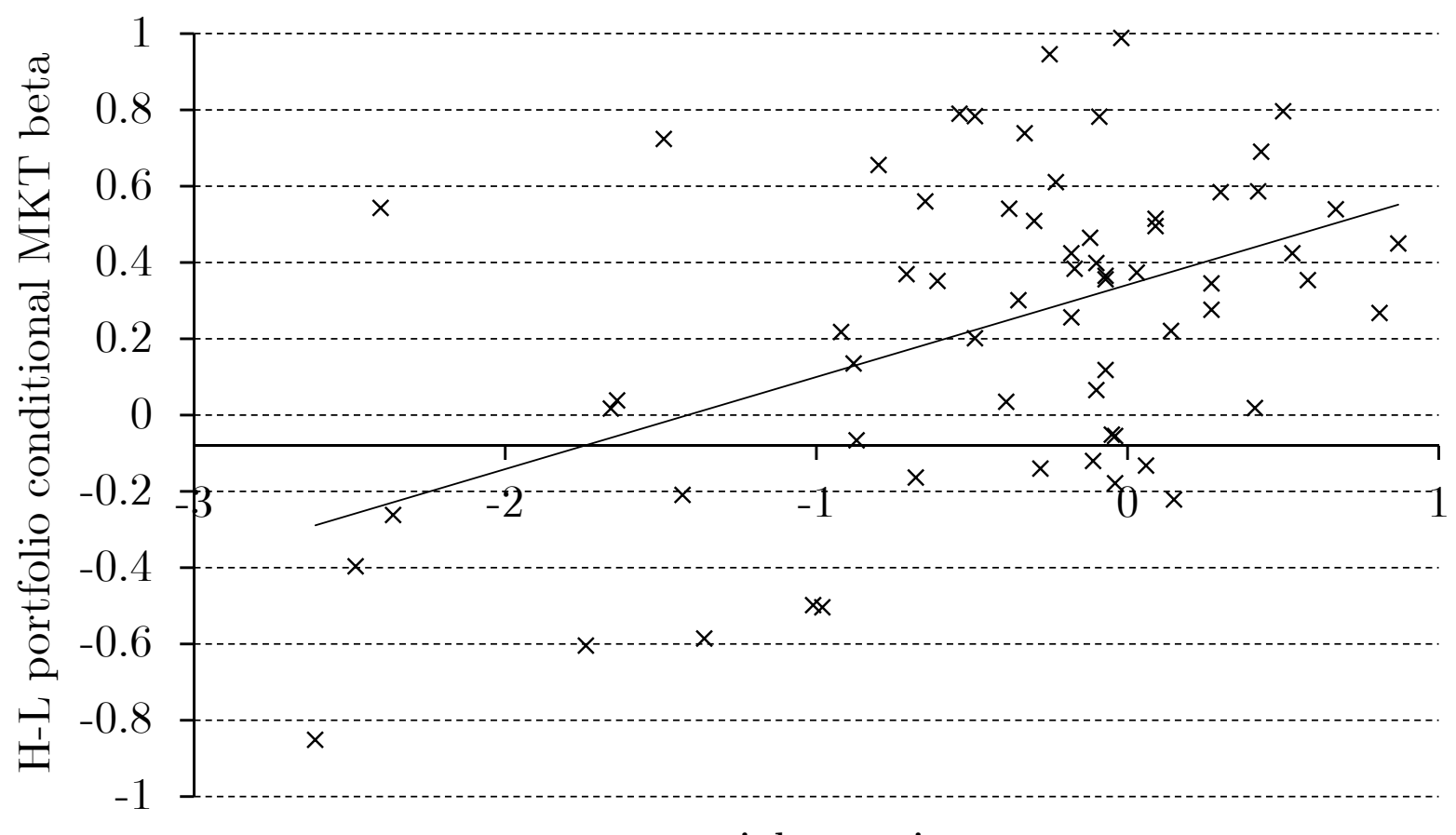

net job creation

linear regression estimates:

$$
\begin{gathered}
\mathrm{y}=0.24 \mathrm{x}+0.34 \\
(4.3) \quad(7.0) \\
\text { R-sq. }=22.6 \%
\end{gathered}
$$

\section{Figure 2. Conditional Beta of LM High Minus Low Portfolio and Net Job Creation}

Quarterly Net Job Creation estimates are described in Davis, Haltiwanger, and Schuh (1998) and obtained from Steven J. Davis' website. Conditional betas of the LM H-L portfolios are estimated every quarter with daily returns, and corrected for non-synchronous trading following the methodology described in Lewellen and Nagel (2006). OLS t-statistics of the regression line shown below the figure are reported in parenthesis. The sample covers the period 1989-2005. 


\section{Table I}

\section{Most Immobile and Most Mobile Occupations}

The table presents the bottom 15 (Panel A) and top 15 (Panel B) five-digit SOC broad occupations sorted on the measure of labor mobility, as of 2011. The ranking excludes occupations that do not require at least a few months of specific preparation (occupations in Job Zone one from $\mathrm{O} *$ NET).

\begin{tabular}{|c|c|c|}
\hline $\mathrm{SOC}$ & Occupation Title & Mobility \\
\hline \multicolumn{3}{|c|}{ Panel A: Bottom 15 Occupations by Labor Mobility } \\
\hline 119130 & Postmasters and Mail Superintendents & 0.01 \\
\hline 131070 & Farm Labor Contractors & 0.01 \\
\hline 394010 & Embalmers & 0.01 \\
\hline 394020 & Funeral Attendants & 0.02 \\
\hline 532030 & Flight Attendants & 0.03 \\
\hline 534040 & Subway and Streetcar Operators & 0.04 \\
\hline 372020 & Building Cleaning Workers, All Other & 0.08 \\
\hline 537110 & Mine Shuttle Car Operators & 0.06 \\
\hline 292020 & Dental Hygienists & 0.08 \\
\hline 519140 & Semiconductor Processors & 0.09 \\
\hline 474020 & Elevator Installers and Repairers & 0.06 \\
\hline 475060 & Roof Bolters, Mining & 0.09 \\
\hline 291010 & Chiropractors & 0.12 \\
\hline 534020 & Railroad Brake, Signal, and Switch Operators & 0.09 \\
\hline 413040 & Travel Agents & 0.12 \\
\hline \multicolumn{3}{|c|}{ Panel B: Top 15 Occupations by Labor Mobility } \\
\hline 111020 & General and Operations Managers & 82.87 \\
\hline 435060 & Production, Planning, and Expediting Clerks & 72.87 \\
\hline 112020 & Marketing Managers & 64.80 \\
\hline 511010 & First-Line Supervisors of Production and Operating Workers & 59.75 \\
\hline 433030 & Bookkeeping, Accounting, and Auditing Clerks & 56.05 \\
\hline 499040 & Industrial Machinery Mechanics & 51.49 \\
\hline 436010 & Executive Secretaries and Executive Administrative Assistants & 51.25 \\
\hline 113050 & Industrial Production Managers & 48.16 \\
\hline 173020 & Drafters, All Other & 45.35 \\
\hline 435070 & Shipping, Receiving, and Traffic Clerks & 45.28 \\
\hline 131020 & Buyers and Purchasing Agents, Farm Products & 45.25 \\
\hline 439060 & Office Clerks, General & 43.67 \\
\hline 519060 & Inspectors, Testers, Sorters, Samplers, and Weighers & 41.25 \\
\hline 514030 & Cutting, Punching, and Press Machine Operators & 40.79 \\
\hline 111010 & Chief Executives & 39.61 \\
\hline
\end{tabular}




\section{Table II}

\section{Most Immobile and Most Mobile Industries}

The table presents the bottom 15 (Panel A) and top 15 (Panel B) four-digit NAICS industries represented in the merged CRSP/Compustat dataset, sorted on the measure of labor mobility, as of 2011.

\begin{tabular}{|c|c|c|}
\hline NAICS & Industry Title & Mobility \\
\hline \multicolumn{3}{|c|}{ Panel A: Bottom 15 Industries by Labor Mobility } \\
\hline 482100 & Rail Transportation & -1.68 \\
\hline 561500 & Travel Arrangement and Reservation Services & -1.58 \\
\hline 812200 & Death Care Services & -1.54 \\
\hline 238200 & Building Equipment Contractors & -1.48 \\
\hline 481100 & Scheduled Air Transportation & -1.44 \\
\hline 611200 & Junior Colleges & -1.32 \\
\hline 481200 & Nonscheduled Air Transportation & -1.30 \\
\hline 611300 & Colleges, Universities, and Professional Schools & -1.27 \\
\hline 212100 & Coal Mining & -1.25 \\
\hline 721100 & Traveler Accommodation & -1.18 \\
\hline 541300 & Architectural, Engineering, and Related Services & -1.11 \\
\hline 515100 & Radio and Television Broadcasting & -1.10 \\
\hline 561200 & Facilities Support Services & -1.09 \\
\hline 713200 & Gambling Industries & -1.07 \\
\hline 611400 & Business Schools and Computer and Management Training & -0.99 \\
\hline \multicolumn{3}{|c|}{ Panel B: Top 15 Industries by Labor Mobility } \\
\hline 315200 & Cut and Sew Apparel Manufacturing & 2.34 \\
\hline 423500 & Metal and Mineral (except Petroleum) Merchant Wholesalers & 1.99 \\
\hline 447100 & Gasoline Stations & 1.96 \\
\hline 425100 & Wholesale Electronic Markets and Agents and Brokers & 1.79 \\
\hline 424600 & Chemical and Allied Products Merchant Wholesalers & 1.70 \\
\hline 532200 & Consumer Goods Rental & 1.69 \\
\hline 424400 & Grocery and Related Product Merchant Wholesalers & 1.63 \\
\hline 334300 & Audio and Video Equipment Manufacturing & 1.48 \\
\hline 312200 & Tobacco Manufacturing & 1.46 \\
\hline 332800 & Metal Heat Treating & 1.44 \\
\hline 423600 & Electrical and Electronic Goods Merchant Wholesalers & 1.42 \\
\hline 314100 & Textile Furnishings Mills & 1.38 \\
\hline 325600 & Soap, Cleaning Compound, and Toilet Preparation Manufacturing & 1.36 \\
\hline 325500 & Paint, Coating, and Adhesive Manufacturing & 1.36 \\
\hline 335100 & Electric Lighting Equipment Manufacturing & 1.36 \\
\hline
\end{tabular}




\section{Table III}

\section{Panel Data Regressions of Employment Growth per Occupation-Industry group on Industry TFP Growth}

The table shows estimates and standard errors of panel data regressions of employment growth per occupation-industry cluster on industry total factor productivity growth (TFPG), a dummy for high inter-industry occupation concentration (Concentration), and occupation-level controls. Preparation is a dummy dummies for occupations with high levels of specific preparation practice respectively, from survey-based measures from The Occupational Information Network ( $\left.\mathrm{O}^{*} \mathrm{Net}\right)$. Wage is a dummy for occupation-industry clusters with high wages relative to average wages in the economy. All employment and wage data is from the Bureau of Labor Statistics. $R$-sq. is adjusted $r$-squared. Standard errors are clustered by occupation. Significance levels are denoted by $(*=10 \%$ level), $(* *$ $=5 \%$ level $)$, and $(* * *=1 \%$ level $)$. The sample covers the period 1989-2010.

\begin{tabular}{lllll}
\hline & I & II & III & IV \\
\hline TFPG & $38.54^{* * *}$ & $38.40^{* * *}$ & $38.89^{* * *}$ & $38.79^{* * *}$ \\
& $(11.63)$ & $(11.63)$ & $(11.62)$ & $(11.62)$ \\
TFPG x Concentration & $-42.45^{* * *}$ & $-51.30^{* * *}$ & $-47.94^{* * *}$ & $-58.44^{* * *}$ \\
& $(10.38)$ & $(11.59)$ & $(10.81)$ & $(11.68)$ \\
TFPG x Concentration x Preparation & & $16.90^{* *}$ & & 1.54 \\
& & $(8.05)$ & & $(8.70)$ \\
TFPG x Concentration x Wage & & & 9.07 & 9.00 \\
& & & $(6.63)$ & $(6.61)$ \\
Fixed Effects & & & & \\
Year & $\mathrm{Y}$ & $\mathrm{Y}$ & $\mathrm{Y}$ & $\mathrm{Y}$ \\
Industry & $\mathrm{Y}$ & $\mathrm{Y}$ & $\mathrm{Y}$ & $\mathrm{Y}$ \\
R-square $(\%)$ & 4.6 & 4.6 & 4.6 & 4.7 \\
Observations & 173,344 & 173,344 & 173,344 & 173,344 \\
\hline
\end{tabular}




\section{Table IV}

\section{Summary Statistics}

The table reports time-series averages of median characteristics of portfolio of firms sorted by labor mobility, LM. Lab. Int. is the logarithm of the ratio of the number of employees divided by PPE. L. Emp. is the logarithm of the number of employees from Compustat. Occ. Prep. is required occupation-specific preparation ("JobZone" from O*NET). \% skill is the fraction of workers in occupations that require considerable occupation-specific preparation ("JobZones" four and five). Years of Formal Edu. is the number of years of posthigh school formal education based on $\mathrm{O}^{*}$ Net data. Union is the percentage of employees covered by union memberships, based on data from unionstats.com. L. Wage is the logarithm of annual wages per worker from The Bureau of Labor Statistics (BLS). $\sigma_{\mathrm{wg}}$ is standard deviation of annual wage growth. $\rho_{\mathrm{wg}, \mathrm{li}}$ and $\rho_{\mathrm{wg}, \mathrm{gdp}}$ are the correlations of annual wage growth with labor income (constructed as in Jagannathan and Wang (1996)) and GDP growth (from the St. Louis Federal Reserve), L.Size is the logarithm of market value of equity plus book value of total debt. L.Asset is the logarithm of book value of assets. $B / M$ is shareholders equity divided by market value of equity. MKT, SMB, HML, and UMD are the risk factors described in Fama and French (1993) and Carhart (1997). Betas are the slopes of univariate 60 month rolling regressions of excess returns on a risk factor. Lev. is the ratio of book value of debt adjusted for cash holdings, as reported in Compustat, divided by the assets. Op. Lev. is operating leverage, defined as the slope of a time-series regression of payments to unit of capital growth on TFP growth, using data from the KLEMS dataset from BLS. HHI is the Herfindahl-Hirschman Index of industry concentration, constructed as in Hou and Robinson (2006). $O C$ is the measure of Organization Capital from Eisfeldt and Papanikolaou (2012). The sample covers the period 1988-2011, except when otherwise noted.

\begin{tabular}{|c|c|c|c|c|c|c|c|c|c|c|c|}
\hline \multicolumn{12}{|c|}{ Panel A: labor related characteristics } \\
\hline $\begin{array}{c}\text { LM } \\
\text { Portfolio }\end{array}$ & LM & Lab. Int. & L. Emp & $\%$ skill. & $\begin{array}{l}\text { Occ. } \\
\text { Prep. }\end{array}$ & $\begin{array}{c}\text { Years } \\
\text { Formal } \\
\text { Edu. }\end{array}$ & Union & L.Wage* & $\sigma_{\mathrm{wg}}{ }^{*}$ & $\rho_{\mathrm{wg}, \mathrm{li}}{ }^{*}$ & $\rho_{\mathrm{wg}, \mathrm{gdp}}{ }^{*}$ \\
\hline $\mathrm{L}$ & -0.97 & 2.91 & 7.07 & 18.95 & 3.01 & 4.04 & 0.11 & 2.37 & 3.45 & 0.25 & 0.06 \\
\hline 4 & 0.76 & 3.73 & 6.67 & 23.92 & 3.08 & 4.08 & 0.09 & 2.37 & 2.64 & 0.28 & 0.09 \\
\hline $\mathrm{H}$ & 1.05 & 3.79 & 6.53 & 28.94 & 3.21 & 4.34 & 0.09 & 2.38 & 2.80 & 0.45 & 0.19 \\
\hline \multicolumn{12}{|c|}{ Panel B: financial and accounting characteristics } \\
\hline $\begin{array}{c}\text { LM } \\
\text { Portfolio }\end{array}$ & L. Size & L. Asset & $\mathrm{B} / \mathrm{M}$ & Lev. & $\begin{array}{r}\text { MKT } \\
\text { Beta }\end{array}$ & $\begin{array}{l}\text { SMB } \\
\text { Beta }\end{array}$ & $\begin{array}{r}\text { HML } \\
\text { Beta }\end{array}$ & $\begin{array}{c}\text { UMD } \\
\text { Beta }\end{array}$ & Op. Lev. & HHI & $\mathrm{OC}$ \\
\hline 3 & 5.13 & 5.00 & 0.48 & 0.27 & 1.31 & 1.39 & -0.32 & -0.39 & 3.24 & 0.13 & 0.82 \\
\hline 4 & 4.98 & 4.90 & 0.50 & 0.27 & 1.32 & 1.42 & -0.30 & -0.39 & 3.39 & 0.16 & 0.91 \\
\hline $\mathrm{H}$ & 4.95 & 4.90 & 0.51 & 0.27 & 1.33 & 1.42 & -0.32 & -0.40 & 3.70 & 0.17 & 0.94 \\
\hline
\end{tabular}

${ }^{*}$ BLS wage data at the industry level is only available for the period 1997-2011. 


\section{Table V}

\section{Panel Data Regressions of Labor Mobility on Median Industry Characteristics}

The table reports estimates of panel data regressions with year effects of labor mobility on median industry characteristics. Variables are defined in Table IV. $R$-sq. is adjusted $r$-squared. Standard errors are clustered by industry. Significance levels are denoted by $(*=10 \%$ level $),(* *=5 \%$ level), and $(* * *=1 \%$ level $)$. The sample covers the period $1988-2011$.

\begin{tabular}{lcccccccc}
\hline & I & II & III & IV & V & VI & VII & VIII \\
\hline Op. Lev. & $0.04^{* * *}$ & $0.05^{* * *}$ & & & & & & \\
& $(0.02)$ & $(0.01)$ & & & & & & \\
Log Size & -0.05 & & -0.05 & & & & & \\
& $(0.06)$ & & $(0.05)$ & & & & & \\
Log B/M & 0.07 & & & 0.15 & & & & \\
& $(0.18)$ & & & $(0.10)$ & & & & \\
MKT Beta & 0.01 & & & & 0.08 & & & \\
& $(0.29)$ & & & & $(0.27)$ & & & \\
Lab. Int. & 0.08 & & & & & 0.07 & & \\
& $(0.06)$ & & & & & $(0.05)$ & 0.23 & \\
Leverage & 0.32 & & & & & & $(0.32)$ & \\
& $(0.46)$ & & & & & & & $-0.08^{* *}$ \\
Union & -0.06 & & & & & & & $(0.04)$ \\
& $(0.04)$ & & & & & Y \\
Year Eff. & $\mathrm{Y}$ & $\mathrm{Y}$ & $\mathrm{Y}$ & $\mathrm{Y}$ & $\mathrm{Y}$ & $\mathrm{Y}$ & $\mathrm{Y}$ & Y \\
R-sq. $\%)$ & 18.3 & 10.8 & 8.7 & 8.9 & 8.0 & 9.1 & 8.6 & 13.4 \\
Obs. & 479 & 581 & 599 & 599 & 576 & 599 & 599 & 497 \\
\hline
\end{tabular}




\section{Table VI}

\section{Panel Data Regressions of Operating Leverage on Labor Mobility}

The table reports estimates and standard errors of panel data regressions with year effects of operating leverage on labor mobility and median industry characteristics at the 3-digit NAICS industry level. $R$-sq. is adjusted $r$-squared. Standard errors are clustered by industry. Significance levels are denoted by $(*=10 \%$ level $),(* *=5 \%$ level $)$, and $(* * *=1 \%$ level $)$. The sample covers the period 1988-2011.

\begin{tabular}{|c|c|c|c|c|c|c|c|c|}
\hline & I & II & III & IV & $\mathrm{V}$ & VI & VII & VIII \\
\hline \multirow[t]{2}{*}{ Mobility } & $0.52^{* *}$ & $0.45^{* *}$ & $0.45^{* * *}$ & $0.43^{* *}$ & $0.45^{* *}$ & $0.46^{* * *}$ & $0.45^{* *}$ & $0.54^{* *}$ \\
\hline & $(0.22)$ & $(0.17)$ & $(0.17)$ & $(0.17)$ & (0.18) & $(0.17)$ & $(0.17)$ & $(0.21)$ \\
\hline \multirow[t]{2}{*}{ Log Size } & 0.13 & & 0.01 & & & & & \\
\hline & $(0.12)$ & & $(0.10)$ & & & & & \\
\hline \multirow[t]{2}{*}{$\log B / M$} & $1.34^{* * *}$ & & & $0.77^{* *}$ & & & & \\
\hline & $(0.42)$ & & & $(0.30)$ & & & & \\
\hline \multirow[t]{2}{*}{ MKT Beta } & $2.10^{* * *}$ & & & & $1.27^{* *}$ & & & \\
\hline & $(0.66)$ & & & & $(0.53)$ & & & \\
\hline \multirow[t]{2}{*}{ Lab. Int. } & -0.01 & & & & & -0.11 & & \\
\hline & $(0.13)$ & & & & & $(0.12)$ & & \\
\hline \multirow[t]{2}{*}{ Leverage } & -1.94 & & & & & & 0.11 & \\
\hline & (1.37) & & & & & & (0.94) & \\
\hline \multirow[t]{2}{*}{ Union } & $0.25^{*}$ & & & & & & & $0.26^{*}$ \\
\hline & $(0.15)$ & & & & & & & $(0.14)$ \\
\hline Year Eff. & Y & $Y$ & Y & $\mathrm{Y}$ & $Y$ & Y & $\mathrm{Y}$ & Y \\
\hline R-sq. (\%) & 8.0 & 2.6 & 2.6 & 4.2 & 3.6 & 2.8 & 2.6 & 3.7 \\
\hline Obs. & 3299 & 4246 & 4246 & 4246 & 4082 & 4246 & 4246 & 3399 \\
\hline
\end{tabular}




\section{Table VII}

\section{Panel Data Regressions of Capital Payment Growth on TFP Growth and Labor Mobility}

The table shows estimates and standard errors of panel data regressions with year and industry fixed effects of capital payment growth on total factor productivity growth (TFPG), labor mobility, and controls. All variables, except for the measure of labor mobility, are obtained from the Multifactor Division program of the Bureau of Labor Statistics at aggregate industrylevels. Investment rate is gross investment over productive capital. Inventory and land are inventory and land scaled by productive capital, respectively. Labor share is the share of labor to output. $R$-sq. is adjusted $r$-squared. Standard errors are clustered by industry. Significance levels are denoted by $(*=10 \%$ level $),(* *=5 \%$ level $)$, and $(* * *=1 \%$ level $)$. The sample covers the period 1988-2008.

\begin{tabular}{lccllll}
\hline & $\mathrm{I}$ & $\mathrm{II}$ & $\mathrm{III}$ & $\mathrm{IV}$ & $\mathrm{V}$ & $\mathrm{VI}$ \\
\hline TFPG & $1.98^{* * *}$ & $1.90^{* * *}$ & $1.89^{* * *}$ & $1.89^{* * *}$ & $1.99^{* * *}$ & $1.89^{* * *}$ \\
& $(0.43)$ & $(0.43)$ & $(0.43)$ & $(0.43)$ & $(0.42)$ & $(0.43)$ \\
Mobility x TFPG & $0.80^{* *}$ & $0.83^{* *}$ & $0.82^{* *}$ & $0.83^{* *}$ & $0.82^{* *}$ & $0.83^{* *}$ \\
& $(0.27)$ & $(0.24)$ & $(0.24)$ & $(0.24)$ & $(0.26)$ & $(0.24)$ \\
Mobility & 0.00 & 0.00 & 0.01 & 0.00 & -0.01 & 0.00 \\
& $(0.02)$ & $(0.03)$ & $(0.03)$ & $(0.03)$ & $(0.03)$ & $(0.03)$ \\
Investment rate & -0.32 & 0.19 & & & & \\
& $(0.50)$ & $(0.61)$ & & & & \\
Inventory & -0.59 & & -0.33 & & & \\
& $(0.48)$ & & $(0.43)$ & & & \\
Land & -0.15 & & & -0.14 & & \\
& $(0.13)$ & & & $(0.15)$ & & $-0.73^{* *}$ \\
Labor share & $-0.80^{* *}$ & & & & $(0.29)$ & \\
& $(0.28)$ & & & & & \\
Fixed Effects & & & & & $\mathrm{Y}$ & $\mathrm{Y}$ \\
Year & $\mathrm{Y}$ & $\mathrm{Y}$ & $\mathrm{Y}$ & $\mathrm{Y}$ & $\mathrm{Y}$ & $\mathrm{Y}$ \\
Industry & $\mathrm{Y}$ & $\mathrm{Y}$ & $\mathrm{Y}$ & $\mathrm{Y}$ & 15.4 & 15.6 \\
R-square $(\%)$ & 16.5 & 15.6 & 15.6 & 15.6 & 1,692 \\
Observations & 1,092 & 1,092 & 1,092 & 1,092 & 1,092 & 1,092 \\
\hline
\end{tabular}


Table VIII

\section{Cross-Section of Returns of Stocks Sorted on Labor Mobility}

The table reports post-ranking mean realized excess monthly stock returns over one-month Treasury bill rates, and adjusted monthly returns of portfolios of stocks sorted on labor mobility lagged one year. Excess are returns minus the one-month Treasury bill and Unlevered are estimated as excess stock returns times one minus lagged leverage ratio (measured using book value of debt and market value of equity). Raw are unadjusted excess returns and $A d j$ are returns adjusted for size, book-to-market, and momentum, according to the methodology in Daniel et al. (1997). H-L is the zero investment portfolio long the portfolio of firms with high labor mobility $(\mathrm{H})$ and short the portfolio of firms with low labor mobility (L). Newey-West standard errors are estimated with one lag. Significance levels are denoted by $(*=10 \%$ level $),(* *=5 \%$ level $)$ and $(* * *=1 \%$ level $)$. The sample covers the period 1989-2011.

\begin{tabular}{lcccccccc}
\hline \multirow{2}{*}{ Portfolio } & \multicolumn{3}{c}{ Excess } & \multicolumn{2}{c}{ Unlevered } & \multicolumn{3}{c}{ Equally weighted } \\
& Raw & Adj. & Raw & Adj. & Raw & Adj. & Raw & Adj. \\
\hline L & 0.46 & -0.21 & 0.22 & -0.13 & 0.77 & -0.13 & 0.36 & -0.09 \\
2 & 0.60 & -0.05 & 0.40 & 0.00 & 0.83 & -0.03 & 0.45 & 0.01 \\
3 & 0.59 & -0.02 & 0.37 & 0.00 & 0.92 & 0.09 & 0.49 & 0.09 \\
4 & 0.74 & 0.10 & 0.51 & 0.10 & 0.98 & 0.05 & 0.60 & 0.11 \\
H & 0.89 & 0.20 & 0.64 & 0.20 & 1.21 & 0.24 & 0.72 & 0.22 \\
H-L & $0.43^{*}$ & $0.41^{* *}$ & $0.42^{* *}$ & $0.33^{* *}$ & $0.43^{* *}$ & $0.37^{* *}$ & $0.36^{* *}$ & $0.31^{* *}$ \\
& $(0.23)$ & $(0.19)$ & $(0.18)$ & $(0.15)$ & $(0.21)$ & $(0.17)$ & $(0.16)$ & $(0.13)$ \\
\hline
\end{tabular}




\section{Table IX}

Panel Data Regressions of Annual Stock Returns on Labor Mobility and Firm Characteristics

The table shows estimates and standard errors of panel data regressions with year effects of stock returns on lagged labor mobility and firm characteristics. Variables are described in Table IV. $R$-sq. is $r$-squared. Standard errors are clustered by firm. Significance levels are denoted by $(*=10 \%$ level $),(* *=5 \%$ level $)$, and $(* * *=1 \%$ level $)$. The sample covers the period 1989-2011.

\begin{tabular}{|c|c|c|c|c|c|c|c|c|c|c|}
\hline & I & II & III & IV & V & VI & VII & VIII & IX & $\mathrm{X}$ \\
\hline \multirow[t]{2}{*}{ Mobility } & $2.02^{* * *}$ & $1.86^{* * *}$ & $1.67^{* * *}$ & $2.02^{* * *}$ & $1.97^{* * *}$ & $1.69^{* * *}$ & $2.16^{* * *}$ & $2.08^{* * *}$ & & \\
\hline & $(0.36)$ & $(0.31)$ & $(0.30)$ & $(0.31)$ & $(0.33)$ & $(0.34)$ & $(0.32)$ & $(0.31)$ & & \\
\hline \multirow[t]{2}{*}{ Log Size } & $-0.41^{* *}$ & & $-1.18^{* * *}$ & & & & & & & \\
\hline & $(0.17)$ & & $(0.14)$ & & & & & & & \\
\hline \multirow[t]{2}{*}{$\log B / M$} & $4.23^{* * *}$ & & & $5.19^{* * *}$ & & & & & $4.24^{* * *}$ & \\
\hline & $(0.50)$ & & & $(0.31)$ & & & & & $(0.40)$ & \\
\hline \multirow[t]{2}{*}{ Lag Ret. } & $-0.03^{* * *}$ & & & & $-0.05^{* * *}$ & & & & $-0.03^{* * *}$ & \\
\hline & $(0.00)$ & & & & $(0.00)$ & & & & $(0.00)$ & \\
\hline \multirow[t]{2}{*}{ MKT Beta } & $2.29^{* *}$ & & & & & $2.59^{* * *}$ & & & $3.11^{* * *}$ & $2.95^{* * *}$ \\
\hline & (1.09) & & & & & $(0.99)$ & & & $(1.00)$ & $(1.00)$ \\
\hline \multirow[t]{2}{*}{ Lab. Int. } & $-0.62^{* * *}$ & & & & & & $-0.68^{* * *}$ & & & \\
\hline & $(0.22)$ & & & & & & $(0.18)$ & & & \\
\hline \multirow[t]{2}{*}{ Leverage } & -2.20 & & & & & & & $8.13^{* * *}$ & & \\
\hline & $(1.76)$ & & & & & & & $(1.22)$ & & \\
\hline Year Eff. & Y & Y & Y & $Y$ & Y & $Y$ & Y & Y & Y & Y \\
\hline R-sq. (\%) & 7.07 & 5.00 & 5.11 & 5.43 & 6.17 & 6.50 & 5.02 & 5.07 & 6.99 & 6.45 \\
\hline Obs. & 43,758 & 67,701 & 67,701 & 67,701 & 56,765 & 44,004 & 67,701 & 67,701 & 43,758 & 44,004 \\
\hline
\end{tabular}




\section{Table X}

\section{Panel Data Regressions of Implied Cost of Capital on Labor Mobility}

The table reports estimates and standard errors of panel data regressions with year effects of measures of cost of capital on lagged labor mobility and firm characteristics. GLS is the cost of capital measure in Gebhardt, Lee, and Swaminathan (2002). WZ is the cost of capital measure of Wu and Zhang (2008). HVDZ is the cost of capital measure of Hou et al. (2012). Remaining variables are defined in Table IV. $R$-sq. is adjusted $r$-squared. Standard errors clustered by firm. Significance levels are denoted by $(*=10 \%$ level $),(* *=5 \%$ level $)$, and $(* * *$ $=1 \%$ level). The sample covers the period 1989-2010.

\begin{tabular}{llllllllll}
\hline Dep. Var. & & GLS & & & WZ & \multicolumn{3}{c}{ HVDZ } \\
& I & II & III & I & II & III & I & II & III \\
\hline Mobility & $0.16^{* * *}$ & $0.12^{* * *}$ & $0.10^{*}$ & $0.21^{* * *}$ & $0.16^{* * *}$ & $0.09^{*}$ & $0.16^{* * *}$ & $0.11^{*}$ & $0.22^{* * *}$ \\
& $(0.04)$ & $(0.04)$ & $(0.05)$ & $(0.03)$ & $(0.03)$ & $(0.05)$ & $(0.05)$ & $(0.06)$ & $(0.07)$ \\
Log Size & $-0.22^{* * *}$ & $-0.24^{* * *}$ & & $0.13^{* * *}$ & $0.21^{* * *}$ & & $-0.86^{* * *}$ & $-0.76^{* * *}$ & \\
& $(0.02)$ & $(0.03)$ & & $(0.02)$ & $(0.02)$ & & $(0.04)$ & $(0.03)$ & \\
Log B/M & $0.81^{* * *}$ & $1.35^{* * *}$ & & $2.06^{* * *}$ & $2.43^{* * *}$ & & $1.40^{* * *}$ & $1.72^{* * *}$ & \\
& $(0.09)$ & $(0.08)$ & & $(0.06)$ & $(0.06)$ & & $(0.09)$ & $(0.08)$ & \\
MKT Beta & $0.49^{* * *}$ & & & $-0.85^{* * *}$ & & & $-1.06^{* * *}$ & & \\
& $(0.10)$ & & & $(0.07)$ & & & $(0.12)$ & & \\
Leverage & $3.26^{* * *}$ & & & $1.97^{* * *}$ & & & $1.54^{* * *}$ & & \\
& $(0.22)$ & & & $(0.16)$ & & & $(0.28)$ & & \\
Year Eff. & $\mathrm{Y}$ & $\mathrm{Y}$ & $\mathrm{Y}$ & $\mathrm{Y}$ & $\mathrm{Y}$ & $\mathrm{Y}$ & $\mathrm{Y}$ & $\mathrm{Y}$ & $\mathrm{Y}$ \\
R-sq. (\%) & 10.0 & 8.4 & 1.3 & 28.5 & 27.2 & 4.3 & 19.9 & 19.4 & 4.1 \\
Obs. & 28,323 & 28,323 & 28,323 & 32,217 & 32,217 & 32,217 & 32,215 & 32,215 & 32,215 \\
\hline
\end{tabular}




\section{Table XI \\ Time-Series Asset Pricing Tests}

This table reports asset pricing tests of the unconditional and conditional CAPM using five portfolios of stocks sorted on labor mobility. The table reports the intercept (monthly alpha) of time-series regressions of excess portfolio returns on the excess market returns. Regressions in the test are corrected for non-synchronous trading following the methodology described in Lewellen and Nagel (2006). Returns are at a monthly frequency. Conditional betas are estimated each calendar year. NeweyWest standard errors are estimated with one lag. Significance levels are denoted by $(*=10 \%$ level $),(* *=5 \%$ level $)$ and $(* * *=$ $1 \%$ level). The sample covers the period 1989-2011.

\begin{tabular}{|c|c|c|c|c|c|c|c|c|c|c|c|c|}
\hline & \multicolumn{6}{|c|}{ Value-weighted portfolios } & \multicolumn{6}{|c|}{ Equally-weighted portfolios } \\
\hline & $\mathrm{L}$ & 2 & 3 & 4 & $\mathrm{H}$ & H-L & $\mathrm{L}$ & 2 & 3 & 4 & $\mathrm{H}$ & $\mathrm{H}-\mathrm{L}$ \\
\hline \multicolumn{13}{|c|}{ Panel A: Excess Returns } \\
\hline$E[R]-r_{f}(\%)$ & $\begin{array}{l}0.46 \\
(0.31)\end{array}$ & $\begin{array}{l}0.60^{*} \\
(0.31)\end{array}$ & $\begin{array}{l}0.59^{*} \\
(0.30)\end{array}$ & $\begin{array}{l}0.74^{* *} \\
(0.34)\end{array}$ & $\begin{array}{l}0.89^{* * *} \\
(0.32)\end{array}$ & $\begin{array}{l}0.43^{*} \\
(0.23)\end{array}$ & $\begin{array}{l}0.77^{*} \\
(0.40)\end{array}$ & $\begin{array}{l}0.83^{*} \\
(0.43)\end{array}$ & $\begin{array}{l}0.92^{*} \\
(0.47)\end{array}$ & $\begin{array}{l}0.98^{* *} \\
(0.42)\end{array}$ & $\begin{array}{l}1.21^{* * *} \\
(0.45)\end{array}$ & $\begin{array}{l}0.43^{* *} \\
(0.21)\end{array}$ \\
\hline \multicolumn{13}{|c|}{ Panel B: Unconditional CAPM } \\
\hline Alpha (\%) & $\begin{array}{l}-0.10 \\
(0.13)\end{array}$ & $\begin{array}{l}0.07 \\
(0.13)\end{array}$ & $\begin{array}{l}0.07 \\
(0.12)\end{array}$ & $\begin{array}{l}0.15 \\
(0.13)\end{array}$ & $\begin{array}{l}0.35^{* *} \\
(0.15)\end{array}$ & $\begin{array}{l}0.44^{*} \\
(0.23)\end{array}$ & $\begin{array}{l}0.06 \\
(0.19)\end{array}$ & $\begin{array}{l}0.05 \\
(0.20)\end{array}$ & $\begin{array}{l}0.13 \\
(0.27)\end{array}$ & $\begin{array}{l}0.24 \\
(0.20)\end{array}$ & $\begin{array}{l}0.42^{*} \\
(0.22)\end{array}$ & $\begin{array}{l}0.37^{* *} \\
(0.18)\end{array}$ \\
\hline MKT Beta & $\begin{array}{l}1.04^{* * *} \\
(0.04)\end{array}$ & $\begin{array}{l}0.98^{* * *} \\
(0.04)\end{array}$ & $\begin{array}{l}0.96^{* * *} \\
(0.04)\end{array}$ & $\begin{array}{l}1.09^{* * *} \\
(0.04)\end{array}$ & $\begin{array}{l}1.01^{* * *} \\
(0.05)\end{array}$ & $\begin{array}{l}-0.03 \\
(0.07)\end{array}$ & $\begin{array}{l}1.33^{* * *} \\
(0.05)\end{array}$ & $\begin{array}{l}1.43^{* * *} \\
(0.06)\end{array}$ & $\begin{array}{l}1.45^{* * *} \\
(0.08)\end{array}$ & $\begin{array}{l}1.37^{* * *} \\
(0.06)\end{array}$ & $\begin{array}{l}1.45^{* * *} \\
(0.06)\end{array}$ & $\begin{array}{l}0.12^{*} \\
(0.05)\end{array}$ \\
\hline R-sq. (\%) & 82.7 & 81.7 & 83.2 & 84.2 & 76.2 & 0.1 & 74.3 & 74.8 & 61.6 & 72.5 & 70.8 & 1.9 \\
\hline \multicolumn{13}{|c|}{ Panel C: Conditional CAPM } \\
\hline Avg. Alpha (\%) & $\begin{array}{l}0.02 \\
(0.11)\end{array}$ & $\begin{array}{l}-0.02 \\
(0.23)\end{array}$ & $\begin{array}{l}0.11 \\
(0.11)\end{array}$ & $\begin{array}{l}0.05 \\
(0.14)\end{array}$ & $\begin{array}{l}0.01 \\
(0.19)\end{array}$ & $\begin{array}{l}-0.01 \\
(0.25)\end{array}$ & $\begin{array}{l}-0.02 \\
(0.29)\end{array}$ & $\begin{array}{l}-0.17 \\
(0.35)\end{array}$ & $\begin{array}{l}0.02 \\
(0.39)\end{array}$ & $\begin{array}{l}0.02 \\
(0.33)\end{array}$ & $\begin{array}{l}0.04 \\
(0.35)\end{array}$ & $\begin{array}{l}0.06 \\
(0.18)\end{array}$ \\
\hline Avg. MKT Beta & $\begin{array}{l}0.98^{* * *} \\
(0.07)\end{array}$ & $\begin{array}{l}1.06^{* * *} \\
(0.11)\end{array}$ & $\begin{array}{l}1.00^{* * *} \\
(0.06)\end{array}$ & $\begin{array}{l}1.17^{* * *} \\
(0.06)\end{array}$ & $\begin{array}{l}1.19^{* * *} \\
(0.09)\end{array}$ & $\begin{array}{l}0.21 \\
(0.15)\end{array}$ & $\begin{array}{l}1.46^{* * *} \\
(0.11)\end{array}$ & $\begin{array}{l}1.63^{* * *} \\
(0.10)\end{array}$ & $\begin{array}{l}1.70^{* * *} \\
(0.13)\end{array}$ & $\begin{array}{l}1.62^{* * *} \\
(0.13)\end{array}$ & $\begin{array}{l}1.72^{* * *} \\
(0.13)\end{array}$ & $\begin{array}{l}0.26^{*} \\
(0.13)\end{array}$ \\
\hline Avg. R-sq. (\%) & 81.5 & 83.2 & 84.5 & 84.4 & 83.7 & 32.7 & 77.5 & 79.6 & 76.1 & 76.8 & 77.6 & 29.8 \\
\hline
\end{tabular}




\section{Table XII}

\section{Time-Series Variation of the Labor Mobility Return Spread}

This table presents results from time-series regressions of the monthly return spread (in basis points) of the equally-weighted H-L portfolio on various asset-pricing factors, business cycle, and labor market indicators. MKT, SMB, HML, and UMD are the market, size, value, and momentum risk factors described in Fama and French (1993) and Carhart (1997), and obtained from Kenneth French website. GDP is demeaned GDP growth rate, obtained from the St. Louis Federal Reserve Economic Database (FRED), and $L . G D P$ is lagged GDP. $P / E$ is demeaned cyclically adjusted ratio of price over earnings from Robert Shiller's website. INF is demeaned monthly rate of inflation, obtained from FRED. TERM is demeaned term spread, the difference between 10-year and 1-year treasury constant maturity rates, obtained from the FRED. UNEMP is demeaned unemployement rate, obtained from the FRED. Newey-West standard errors are estimated with one lag. Significance levels are denoted by $(*=10 \%$ level $)$, $(* *=5 \%$ level), and $(* * *=1 \%$ level). The sample covers the period 1989-2011.

\begin{tabular}{|c|c|c|c|c|c|c|c|c|c|c|c|}
\hline & I & II & III & IV & $\mathrm{V}$ & VI & VII & VIII & IX & $\mathrm{X}$ & XI \\
\hline Intercept & $\begin{array}{l}0.43^{\text {** }} \\
(0.21)\end{array}$ & $\begin{array}{l}0.39^{*} \\
(0.20)\end{array}$ & $\begin{array}{l}0.38^{* *} \\
(0.19)\end{array}$ & $\begin{array}{l}0.52^{* * *} \\
(0.20)\end{array}$ & $\begin{array}{l}0.36^{*} \\
(0.19)\end{array}$ & $\begin{array}{l}0.43^{* *} \\
(0.21)\end{array}$ & $\begin{array}{l}0.43^{* *} \\
(0.21)\end{array}$ & $\begin{array}{l}0.43^{\text {** }} \\
(0.21)\end{array}$ & $\begin{array}{l}0.43^{* *} \\
(0.21)\end{array}$ & $\begin{array}{l}0.43^{\text {** }} \\
(0.21)\end{array}$ & $\begin{array}{l}0.43^{\text {** }} \\
(0.21)\end{array}$ \\
\hline MKT & & $\begin{array}{l}0.08^{*} \\
(0.05)\end{array}$ & & & & & & & & & \\
\hline SMB & & & $\begin{array}{l}0.35^{\text {*** }} \\
(0.07)\end{array}$ & & & & & & & & \\
\hline HML & & & & $\begin{array}{c}-0.41^{* * *} \\
(0.10)\end{array}$ & & & & & & & \\
\hline UMD & & & & & $\begin{array}{l}0.10^{*} \\
(0.05)\end{array}$ & & & & & & \\
\hline GDP & & & & & & $\begin{array}{l}-0.10 \\
(0.09)\end{array}$ & & & & & \\
\hline L.GDP & & & & & & & $\begin{array}{l}-0.13 \\
(0.09)\end{array}$ & & & & \\
\hline $\mathrm{P} / \mathrm{E}$ & & & & & & & & $\begin{array}{l}1.11 \\
(1.06)\end{array}$ & & & \\
\hline INF & & & & & & & & & $\begin{array}{l}0.13 \\
(0.53)\end{array}$ & & \\
\hline TERM & & & & & & & & & & $\begin{array}{l}-0.04 \\
(0.17)\end{array}$ & \\
\hline UNEMP & & & & & & & & & & & $\begin{array}{c}-0.16 \\
(0.14)\end{array}$ \\
\hline R-Square & 0.00 & 1.57 & 15.18 & 19.30 & 3.03 & 0.29 & 0.56 & 0.35 & 0.02 & 0.03 & 0.69 \\
\hline Obs. & 276 & 276 & 276 & 276 & 276 & 276 & 276 & 276 & 276 & 276 & 276 \\
\hline
\end{tabular}

